\title{
RECENED
}

OSTI

\section{Quarterly Report on the Ferrocyanide Safety Program for the Period Ending March 31, 1995}

Prepared for the U.S. Department of Energy Office of Environmental Restoration and Waste Management

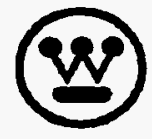

Westinghouse

Hanford Company Richland, Washington

Hanford Operations and Engineering Contractor for the

U.S. Department of Energy under Contract DE-ACO6-87RL10930

Approved for Public Release

DSTRRBUTOU OF THIS DOCUMENT IS UNUMITED GH 
LEGAL DISCLAIMER

This report was prepared as an account of work sponsored by an agency of the United States Government. Neither the United States Government nor any agency thereof, nor any of their employees, nor any of their contractors, subcontractors or their employees, makes any werranty, express or implied, or assumes any legal liability or responsibility for the

accuracy, completeness, or any third party's use or the results of such use of any information, apparatus, product, or process disclosed, or represents that its use would not infringe privately owned rights. Reference herein to any specific commercial product, process, or service by trade name, trademark, manufacturer, or otherwise, does not necessarily constitute or imply its endorsement, recommendation, or favoring by the United States Government or any agency thereof or its contractors or subcontractors. The views and opinions of authors expressed herein do not necessarily state or reflect those of the United States Government or any agency thereof.

This report has been reproduced from the best available copy. Available in paper copy and microfiche.

Available to the U.S. Department of Energy

and its contrectors from

Office of Scientific and Technical Information

P.O. Box 62

Ork Ridge, TN 37831

(615) $576-8401$

Available to the public from the U.S. Department of Commerce National Technical Information Service

5285 Port Royal Rosd

Springfield, VA 22161

(703) 487-4650

Printed in the United Stutes of Americe

DISCLM-1.CHP (1-91) 


\section{DISCLAIMER}

Portions of this document may be illegible in electronic image products. Images are produced from the best available original document. 


\title{
Quarterly Report on the Ferrocyanide Safety Progam for the Period Ending March 31, 1995
}

\author{
R. J. Cash \\ J. E. Meacham \\ G. T. Dukelow
}

Date Published

April 1995

Prepared for the U.S. Department of Energy Office of Environmental Restoration and Waste Management

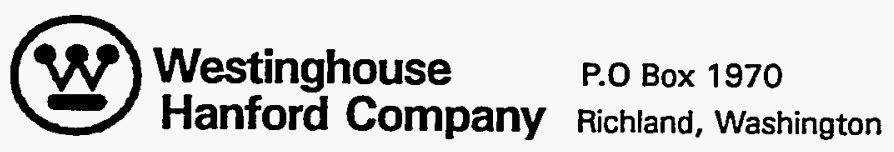

Hanford Operations and Engineering Contractor for the

U.S. Department of Energy under Contract DE-AC06-87RL10930 


\section{RELEASE AUTHORIZATION}

Document Number: WHC-EP-0474-16

Document Title: Quarterly Report on the Ferrocyanide Safety Program for the Period Ending March 31, 1995

Release Date: $\quad 4 / 27 / 95$

This document was reviewed following the procedures described in WHC-CM-3-4 and is:

APPROVED FOR PUBLIC RELEASE

WHC Information Release Administration Specialist:

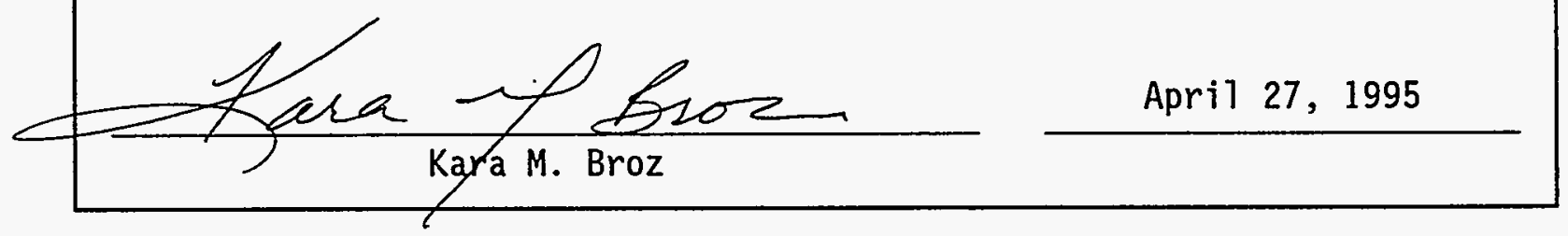




\title{
QUARTERLY REPORT ON THE FERROCYANIDE SAFETY PROGRAM FOR THE PERIOD ENDING MARCH 31, 1995
}

\author{
R. J. Cash \\ J. E. Meacham \\ G. T. Dukelow
}

\begin{abstract}
This is the sixteenth quarterly report on the progress of activities addressing the Ferrocyanide

- Safety Issue associated with Hanford Site high-level radioactive waste tanks. Progress in the Ferrocyanide Safety Program is reviewed, including work addressing the six parts of Defense Nuclear Facilities Safety Board Recommendation 90-7 (FR 1990). All work activities are described in the revised program plan (DOE 1994b), and this report follows the same format presented there. A summary of the key events occurring this quarter is presented in Section 1.2. More detailed discussions of progress are located in Sections 2.0 through 4.0.
\end{abstract}


WHC-EP-0474-16

This page intentionally left blank. 


\section{CONTENTS}

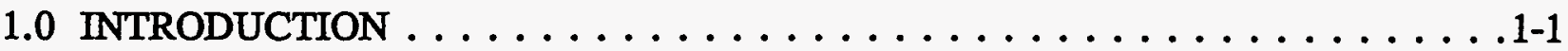

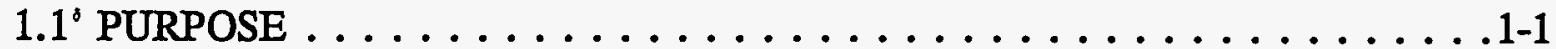

1.2 QUARTERLY HIGHLIGHTS . . . . . . . . . . . . . . 1-1

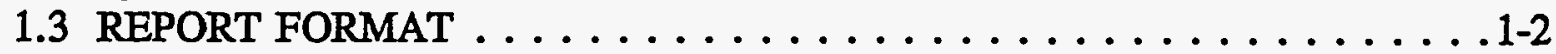

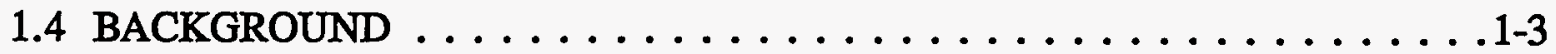

2.0 FERROCYANIDE SAFETY DOCUMENTATION $\ldots \ldots \ldots \ldots \ldots \ldots$

3.0 ACTIONS TO COMPLETE DNFSB RECOMMENDATION 90-7 . . . . . . . 3-1

3.1 ENHANCED TEMPERATURE MEASUREMENT $\ldots \ldots \ldots \ldots \ldots \ldots$. . . .

3.1.1 Instrument Trees . . . . . . . . . . . . . . . . . 3-1

3.1.2 Upgrades to Existing Temperature Monitoring Instrumentation . . . . 3-3

3.1.3 Hot Spot Thermal Modeling . . . . . . . . . . . . 3-3

3.1.4 Infrared Scanning System . . . . . . . . . . . . . . . 3-4

3.2 CONTINUOUS TEMPERATURE MONITORING . . . . . . . . . 3-5

3.3 COVER GAS MODELING $\ldots \ldots \ldots \ldots \ldots \ldots \ldots \ldots \ldots \ldots . \ldots \ldots$

3.3.1 Interim Flammable Gas Monitoring . . . . . . . . . . 3-6

3.3.2 Continuous Gas Monitoring . . . . . . . . . . . . 3-7

3.4 FERROCYANIDE WASTE CHARACTERIZATION . . . . . . . . 3-8

3.4.1 Ferrocyanide Tank Waste Sampling and Analyses . . . . . . . . . 3-9

3.4.2 Estimation of Moisture Content . . . . . . . . . . . . 3-20

3.4.3 Moisture Retention Properties of Ferrocyanide Sludge and Saltcake

Simulants . . . . . . . . . . . . . . . . . 3-27

3.5 CHEMICAL REACTION STUDIES . . . . . . . . . . . . . 3-33

3.5.1 Chemical Reaction Studies at Pacific Northwest Laboratory . . . . . 3-33

3.5.2 Preparation and Characterization of Ferrocyanide Simulants . . . . . 3-39

3.6 EMERGENCY RESPONSE PLANNING . . . . . . . . . 3-41

4.0 IMPLEMENTATION OF THE WYDEN AMENDMENT $\ldots \ldots \ldots \ldots \ldots \ldots$. . . . . 4-1

4.1 THE WATCH LIST $\ldots \ldots \ldots \ldots \ldots \ldots \ldots \ldots \ldots \ldots . . \ldots \ldots$

4.2 TEMPERATURE MONITORING $\ldots \ldots \ldots \ldots \ldots \ldots \ldots \ldots$ 4-3

4.3 PRESSURE MONITORING $\ldots \ldots \ldots \ldots \ldots \ldots \ldots \ldots \ldots .4$

5.0 PROGRAM SCHEDULES AND MILESTONES $\ldots \ldots \ldots \ldots \ldots \ldots \ldots . . \ldots$ 5-1

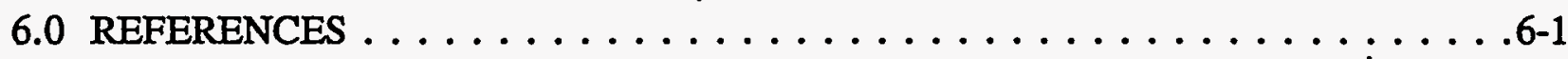

APPENDIX A

FERROCYANIDE TANK INFORMATION SUMMARY $\ldots \ldots \ldots \ldots \ldots \ldots$ A-1 


\section{LIST OF FIGURES}

3-1 Photograph of Four Tank Waste Simulants Showing Color Variations Among

Samples as a Function of Weight Percent Moisture . . . . . . . . . . . 3-13

3-2 Spectra of Waste Samples From Tanks BY-108, C-102, C-103, and C-108 . . . 3-15

3-3 Expanded Spectra for Tank BY-108 Saltcake Waste Containing 4 wt\% Moisture . 3-16

3-4 Comparison of Measured and Model Predicted Responses of the Near-Field

Thermal Neutron Probe to 15, 20, 25, and 100 wt\% Water Simulant . . . . . . 3-22

3-5 Ammonia Production During In-Farm-1B Hydrolysis at 90 and $100^{\circ} \mathrm{C}$. Data from Irradiated and Non-Irradiated Experiments are Shown . . . . . . . . 3-35

3-6 Change in Total [Fe] During the Hydrolysis of In-Farm-1B at $100^{\circ} \mathrm{C}$. Data from Gamma-Irradiated and Non-Irradiated Experiments are Shown . . . . . . . 3-36

3-7 Ammonia Production During the Hydrolysis of $\mathrm{K}_{2} \mathrm{Ni}(\mathrm{CN})_{4}$ at $90{ }^{\circ} \mathrm{C}$. Data From Gamma-Irradiated $\left(1.07 \times 10^{5} \mathrm{Rad} / \mathrm{h}\right.$ Incident Dose Rate) and Non-Irradiated Experiments are Shown. . . . . . . . . . . . . . . . 3-37

5-1 Ferrocyanide Waste Tank Safety Schedule $\ldots \ldots \ldots \ldots \ldots \ldots . . \ldots$ 5-2

\section{LIST OF TABLES}

3-1 Analyses of Auger Samples From Tank 241-C-108 . . . . . . . . . . . . 3-10

3-2 Analyses of Auger Samples From Tank 241-TY-104 . . . . . . . . . . . . 3-10

3-3 Effect of Cesium Concentration on the Cesium Distribution Coefficients for U-Plant-2 Simulant at $\mathrm{pH} 9 . \ldots \ldots \ldots \ldots \ldots \ldots \ldots \ldots \ldots . . \ldots \ldots$

3-4 Analyses of Single-Phase $\mathrm{Na}_{2} \mathrm{NiFe}\left(\mathrm{CN}_{6}\right)_{6}$ Test Batch . . . . . . . . 3-40

A-1 Summary of Contents and Status of Ferrocyanide Tanks $\ldots \ldots \ldots \ldots \ldots$ A-3

A-2 Ferrocyanide Tank Vapor Sampling Summary $\ldots \ldots \ldots \ldots \ldots$ A $\ldots \ldots$ 


\section{LIST OF TERMS}

CASS

CCSEM

CTI

DNFSB

DOE

DSC

EA

EMI

FAI

FO

FTIR

FY

g-mole

GAO

IR

ISB

ILL

I/O

$\mathrm{kW}$

LANL

LOW

NASA

NIR

PLS

PNL

ppmv

$\mathrm{Rad} / \mathrm{h}$

SA

SAR

SEM

SST

TC

TMACS

USQ

vol\%

VSS

WSU

$w t \%$
Computer Automated Surveillance System

Computer Controlled Scanning Electron Microscopy

Contact Temperature Ignition

Defense Nuclear Facilities Safety Board

U.S. Department of Energy

Differential Scanning Calorimetry

Environmental Assessment

Electromagnetic Induction

Fauske and Associates, Inc.

Fiber Optic

Fourier Transform Infrared

Fiscal Year

Gram-Mole

U.S. General Accounting Office

Infrared

Interim Safety Basis

Interstitial Liquid Level

Input/Output

Kilowatt

Los Alamos National Laboratory

Liquid Observation Well

National Aeronautics and Space Administration

Near Infrared

Partial Least Squared

Pacific Northwest Laboratory

Parts Per Million By Volume

Rad Per Hour

Safety Assessment

Safety Analysis Report

Scanning Electron Microscope/Microscopy

Single-Shell Tank

Thermocouple

Tank Monitor and Control System.

Unreviewed Safety Question

Volume Percent

Vapor Sampling System

Washington State University

Weight Percent 
WHC-EP-0474-16

This page intentionally left blank. 


\subsection{INTRODUCTION}

\subsection{PURPOSE}

This quarterly report provides a status of the activities underway on the Ferrocyanide Safety Issue at the Hanford Site, including actions in response to Defense Nuclear Facilities Safety Board (DNFSB) Recommendation 90-7 (FR 1990). In March 1991, a DNFSB implementation plan (Cash 1991) responding to the six parts of Recommendation 90-7 was prepared and sent to the DNFSB. A Ferrocyanide Safety Program Plan addressing the total Ferrocyanide Safety Program, including the six parts of DNFSB Recommendation 90-7, was released in October 1994 (DOE 1994b). Activities in the program plan are underway or have been completed, and the status of each is described in Sections 2.0 and 3.0 of this report.

\subsection{QUARTERLY HIGHLIGHTS}

- An instrument tree was installed in tank 241-TY-104 this quarter. This was the second of seven instrument trees scheduled for installation in ferrocyanide tanks this fiscal year.

- Vapor samples were taken from tank 241-T-107 this quarter. Analyses showed 125 parts per million by volume (ppmv) ammonia, $42 \mathrm{ppmv}$ nitrous oxide, and $1.4 \mathrm{mg} / \mathrm{m}^{3}$ of total non-methane organic compounds.

- Preliminary analyses of the small amount $(-5 \mathrm{~cm})$ of sludge obtained from tank 241-BY-106 revealed a high weight percent (wt\%) moisture (37 wt\%) and notable exothermic energy $(670,1400$, and $670 \mathrm{~J} / \mathrm{g})$. The energy concentration was about that expected for non-aged ferrocyanide waste. However, this tank has also received significant organic material (Toth et al. 1995). Analyses for total organic carbon, total cyanide, and nickel are currently being conducted to determine the source of the exotherm.

- Two auger samples were taken from two different risers in tank 241-C-111 and tank 241-TY-104 this quarter. Recovery for the 241-C-111 auger samples was 33 and $100 \%$, and recovery for the 241-TY-104 auger samples was 67 and $100 \%$.

- Safety screening analyses were completed for samples taken from tanks $241-\mathrm{C}-108$ and 241-TY-104 this quarter. Two of the eight quarter-segments taken from 241-C-108 had measurable exotherms ( 43 and $109 \mathrm{~J} / \mathrm{g}$ ). No exotherms were measured in the 241-TY-104 samples. Samples from both tanks contained considerable moisture. 
- Calibration testing was completed using four waste simulants having a moisture content ranging from 0 to $60 \mathrm{wt} \%$ and the near infrared (NIR) spectroscopy system developed by the Savannah River Laboratory. Speciation tests were also conducted on four tank waste samples at the Westinghouse Hanford Company 222-S Laboratory. Both sets of test results show a strong correlation with moisture content, indicating the NIR spectroscopy can be used to measure the moisture content of the waste.

- A computer-controlled scanning electron microscope (SEM) was purchased, assembled, and acceptance tested this quarter. Non-acceptable performance was noted in the specimen stage sub-system, disk input/output $(\mathrm{I} / \mathrm{O})$ sub-system, and in magnification calibration. Resolutions have been defined for these performance errors and the SEM should be ready for initial testing early next quarter.

- Calibration was completed this quarter for the neutron prototype probes. Calibrations were completed in simulants that contain many of the same elements expected in ferrocyanide waste. With calibration completed, modeling started this quarter to interpret moisture concentrations from the neutron scans of the ferrocyanide tanks measured to date.

- An activity to determine moisture retention and distribution in saltcake waste was started this quarter. A critical review of the available literature on Hanford Site saltcake waste was completed, and efforts are focused on developing a model for moisture retention and distribution after interim stabilization (i.e., after removal of the interstitial liquid).

- Pacific Northwest Laboratory (PNL) work resumed in the 325 Building this quarter. The cyanide speciation and cesium uptake tasks recommenced in late January 1995. These tasks are expected to be completed in July 1995.

- A test batch of single-phase disodium mononickel ferrocyanide $\left[\mathrm{Na}_{2} \mathrm{NiFe}(\mathrm{CN})_{6}\right]$ was prepared this quarter. Analyses indicated that the purity of the material was acceptable. About $300 \mathrm{~g}$ of this material will be made next quarter and shipped to Fauske and Associates, Inc. (FAI) to finish the task on chemical reaction studies.

\subsection{REPORT FORMAT}

Progress reports for activities under each of the six parts of DNFSB Recommendation 90-7 are arranged in the same order as the program plan (DOE 1994b). The arrangement also follows the same order provided in Recommendation 90-7. To report on progress, each part of the recommendation is repeated in italics, followed by paragraphs explaining the scope of work on each part or subpart of the recommendation. Subheadings for each task activity report the following: 
- Progress During Reporting Period

- Planned Work for Subsequent Months

- Problem Areas and Action Taken

- Milestone Status.

\subsection{BACKGROUND}

Various high-level radioactive wastes from defense operations have accumulated at the Hanford Site in underground storage tanks since the mid-1940s. During the 1950s, additional tank storage space was required to support the defense mission. To obtain this additional storage volume within a short time period, and to minimize the need for constructing additional storage tanks, Hanford Site scientists developed a process to scavenge ${ }^{137} \mathrm{Cs}$ and ${ }^{90} \mathrm{Sr}$ from tank waste liquids. In implementing this process, approximately 140 metric tons (154 tons) of ferrocyanide were added to waste that was later routed to a number of Hanford Site single-shell tanks (SSTs) (Sloat 1954, 1955).

In the presence of oxidizing material such as sodium nitrate and/or nitrite, ferrocyanide can be made to react exothermically by heating it to high temperatures or by applying an electrical spark of sufficient energy (Cady 1993). However, fuel, oxidizers, and temperature are all important parameters. If fuel, oxidizers, or high temperatures (initiators) are not present in sufficient amounts, then a runaway or propagating reaction cannot occur.

In 1990, little was known about the potential hazards of a ferrocyanide-nitrate/nitrite reaction in Hanford Site SSTs. Because the safety envelope was not adequately defined by existing analyses, an inadequacy existed in the authorization basis ${ }^{1}$. That is, the existing safety analysis report (Smith 1986) and subsequent analyses such as the 1987 Environmental Impact Statement (DOE 1987) did not adequately define the conditions necessary to preclude propagating reactions in the ferrocyanide waste; therefore, an unreviewed safety question (USQ) was declared (Deaton 1990).

Based on the knowledge gained from simulant studies, theoretical analyses, and analyses of actual waste samples, safety criteria were defined for the ferrocyanide waste (Postma et al. 1994a). These criteria were reviewed and accepted by outside reviewers and reviewers within the U.S. Department of Energy (DOE). The USQ was closed on March 1, 1994 by the DOE Assistant Secretary for Environmental Restoration and Waste Management (Sheridan 1994a).

${ }^{1}$ The DOE authorization basis characterizes the facility design basis and operational requirements for each nuclear facility. The authorization basis is described in documents such as facility safety analysis.reports and other safety analyses, hazard classification documents, technical safety requirements, DOE issued safety evaluation reports, and facility-specific commitments, such as safety assessments for specific tank operations and the Interim Safety Basis (Wagoner 1993). 
In September 1990, an Ad Hoc Task Force report (Kress et al. 1990) recommended that studies be performed to provide information on: (1) the potential for a ferrocyanidenitrate/nitrite explosion; (2) the conditions necessary in the tanks to initiate an explosion; and (3) the potential consequences of such an occurrence. The U.S General Accounting Office (GAO) advised the Secretary of Energy to implement these recommendations (Peach 1990). A closeout report addressing all three of the GAO recommendations was submitted to DOE in June 1994 (Payne 1994a). The report summarizes the progress made on determining the potential for ferrocyanide reactions in Hanford Site ferrocyanide tanks, and the conditions necessary to sustain an exothermic ferrocyanide reaction.

In March 1989 (Nguyen 1989), using process knowledge, process records, transfer records, and $\log$ books, 22 Hanford Site tanks were identified as potentially containing $1,000 \mathrm{gram}$-moles (g-moles) $)^{2}[211 \mathrm{~kg}(465 \mathrm{lb})]$ or more of ferrocyanide [as the $\mathrm{Fe}(\mathrm{CN})_{6}^{4}$ anion]. Two additional ferrocyanide tanks were identified in January 1991 (Borsheim and Cash 1991), increasing the number of ferrocyanide tanks to 24. To avert possible injury to personnel and damage to the facility or environment, strict controls were identified for these and other safety issue tanks in the Operating Specifications for Watch List Tanks (WHC 1990). Tanks identified via this document [see WHC (1994) for the latest revision] have been commonly referred to as Watch List tanks. In October 1990 (Deaton 1990), the Ferrocyanide Safety Issue was declared a USQ (see Section 2.1) because the safety envelope for these tanks was no longer considered to be bounded by the existing safety analysis report (Smith 1986).

In November 1990, the Wyden Amendment (Public Law 101-510, Section 3137, 1990) was enacted. This law required the identification of Hanford Site tanks that may have a serious potential for release of high-level waste (see Section 4.0). In February 1991 (Harmon 1991), the 24 ferrocyanide tanks were among the tanks identified, and were included in the subsequent July 1991 report to Congress (Watkins 1991) that responded to the Wyden Amendment. However, re-examination of the historical records (Borsheim and Simpson 1991) indicated that six of the 24 tanks did not contain the requisite $1,000 \mathrm{~g}$-moles of ferrocyanide. Therefore, these six tanks should not have been included on the Watch List nor been identified in the response to the Wyden Amendment. The six tanks were subsequently removed from the Watch List (Anttonen 1993, Sheridan 1994b).

${ }^{2}$ The $1,000 \mathrm{~g}$-moles criterion has since been replaced with a $115 \mathrm{cal} / \mathrm{g}$ fuel concentration criterion. See Section 4.1 for discussion. 


\subsection{FERROCYANIDE SAFETY DOCUMENTATION}

The USQ process depends on an authorization basis that describes those aspects of the facility design basis and operational requirements relied on by DOE to authorize operation. The authorization basis is described in documents such as facility safety analysis reports (SARs) and other safety analyses, hazard classification documents, technical safety requirements, DOE-issued safety evaluation reports, and facility-specific commitments, such as safety assessments (SAs) and the interim safety basis (ISB). The potential hazards of a ferrocyanide-nitrate/nitrite reaction were discovered to represent an inadequacy in the authorization basis (Smith 1986). The Ferrocyanide USQ was closed on March 1, 1994 by the DOE Assistant Secretary for Environmental Restoration and Waste Management (Sheridan 1994a). Progress on the remaining safety documentation for resolving the Ferrocyanide Safety Issue is reviewed in this section.

Safety and Environmental Assessments. SAs are documents prepared to provide the technical basis to assess the safety of a proposed activity and to provide proper controls to maintain safety. The SA and the accompanying environmental assessment (EA) for that operation provide the basis for DOE authorization of the proposed activities. SAs have been approved for dome space sampling of all ferrocyanide tanks, waste surface sampling, push-mode and rotary-mode core sampling, thermocouple (TC)/instrument tree installation in sound and assumed leaker tanks, and removal of pumpable liquid (interim stabilization). A generic EA covering all proposed operations in the tank farms was approved and a Finding of No Significant Impact issued by DOE (Gerton 1994). Approval of the generic EA provides adequate National Environmental Policy Act coverage for the planned Ferrocyanide Safety Program activities.

The authorization basis for intrusive tank operations was combined into one document, the ISB, which was approved in November 1993 (Wagoner 1993). Safety documentation concerning the ferrocyanide hazard was updated to reflect the approved ferrocyanide safety criteria and closure of the Ferrocyanide USQ.

Hazard Assessment. A report assessing the ferrocyanide waste tank hazards was issued in July 1992 (Grigsby et al. 1992). The report reviewed the understanding of the ferrocyanide hazard at that time, and presented an integrated evaluation and interpretation of historical data and then-available information. Many more data are now available on the potential for exothermic ferrocyanide reactions in Hanford Site SSTs. A final ferrocyanide hazard assessment will be submitted to DOE (tentatively planned for December 1995) as a technical basis to remove the remaining ferrocyanide tanks from the Watch List. Technical information from all Ferrocyanide Safety Program tasks will be compiled into this document.

Ferrocyanide Program Plan. A ferrocyanide program plan was submitted to the DNFSB this quarter (O'Leary 1994). The program plan outlines activities planned to address DNFSB Recommendation 90-7, to meet the Wyden Amendment requirements (Public Law 101-510, Section 3137,1990 ), and to remove the remaining ferrocyanide tanks from the Watch List. 
All ferrocyanide program activities are scheduled to be completed by the end of Fiscal Year (FY) 1997. However, an increased understanding of radiolytic and chemical degradation (aging) of ferrocyanide indicates that little ferrocyanide remains, and the assumption that core sampling of all the tanks is required may not be valid. Core sampling and analyses of only those tanks that bound aging (i.e., tanks with conditions least conducive to aging) could result in resolution of the Ferrocyanide Safety Issue much earlier and at a substantially reduced cost. As more core sample data become available, the need to sample all the ferrocyanide tanks will be reexamined. 


\subsection{ACTIONS TO COMPLETE DNFSB RECOMMENDATION 90-7}

This section follows the format of the program plan (DOE 1994b) and describes all work associated with the Ferrocyanide Safety Program. Where applicable, each task activity is described relative to the DNFSB Recommendation (90-7.1 through 90-7.6). The specific part of the recommendation is given, followed by a summary of activities underway to respond to that part of Recommendation 90-7 (if not already closed out).

\subsection{ENHANCED TEMPERATURE MEASUREMENT}

"Immediate steps should be taken to add instrumentation as necessary to the SSTS containing ferrocyanide that will establish whether hot spots exist or may develop in the future in the stored waste. The instrumentation should include, as a minimum, additional thermocouple trees. Trees should be introduced at several radial locations in all tanks containing substantial amounts of ferrocyanide, to measure the temperature as a function of elevation at these radii. The use of infrared techniques to survey the surface of waste in tanks should continue to be investigated as a priority matter, and on the assumption that this method will be found valuable, monitors based on it should be installed now in the ferrocyanide bearing tanks."

\subsubsection{Instrument Trees}

Work in several areas has developed a broader knowledge base and has warranted several changes in the approach to implementing this recommendation. Originally, it was planned to add several temperature measurement instruments to each tank. This plan has been modified to ensure that at least one instrument tree with replaceable temperature-sensing elements is in each ferrocyanide tank. Additionally, at least two operational temperature-sensing elements should be in the waste to ensure a true temperature measurement, and one or more elements should be in the dome space.

The new data that have warranted this action include the following: (1) many of the TC elements in the existing trees have been returned to service, and measured temperatures are as expected; (2) thermal modeling to date (McLaren 1994a, 1994b) and an enhanced understanding of waste properties show that formation of hot spots in ferrocyanide tanks is not credible (Dickinson et al. 1993, Epstein et al. 1994); and (3) new calculations of tank heat content based on tank temperatures show lower values than previous estimates (Crowe et al. 1993, McLaren 1994a, 1994b).

When all instrument trees are installed, there will be two instrument trees in all but three ferrocyanide tanks (241-BY-106, -111 and -112). Tanks 241-BY-105 and -106 already contain instrument trees with replaceable temperature-sensing elements. Earlier, tanks 241-BY-111 and -112 had no operable instrument trees, and the waste temperatures 
were measured via a dedicated TC element installed in each tank's liquid observation well (LOW). New instrument trees with replaceable temperature-sensing elements were installed in these two tanks in March 1993. The existing instrument trees in the ferrocyanide tanks will be monitored in addition to newly installed trees. The older trees are expected eventually to fail in a manner such that they cannot be repaired, and they will undoubtedly not be replaced.

- Progress During Reporting Period. The second of seven instrument trees to be installed in ferrocyanide tanks this fiscal year was installed in tank 241-TY-104 on March 6, 1995. The ultrahigh-pressure borehead designed for inserting trees into assumed leaker tanks (Hertelendy 1993) was not used for this application because the waste depth was quite shallow [approximately $60 \mathrm{~cm}(2 \mathrm{ft})$ ] and the amount of water required would be well below the 5,600-L (1,500-gal) limit recommended by the Washington Department of Ecology. Approximately 130 L (35 gal) of water were required to insert the instrument tree into the tank waste.

The remaining five instrument trees yet to be installed were fabricated last quarter. Each of these trees contains a heated vapor sampling tube for gathering tank gas samples as required. All equipment and safety documentation supporting insertion of the remaining trees has been completed. Installation of instrument trees in the remaining assumed leaker tanks will continue after: (1) the respective tanks have been core sampled; (2) it is determined that an adequate number of risers are available; or (3) it is determined that risers can be used that are not accessible to the core sampling truck.

- Planned Work for Subsequent Months. Five instrument trees will be installed into the remaining assumed leaker ferrocyanide tanks. The remaining five trees in tanks 241-BY-103, 241-BY-108, 241-C-111, 241-TY-101, and 241-TY-103 are expected to be installed before August 1995. Completion of the milestones listed below requires that the respective instrument trees be connected to the Tank Monitor and Control System (TMACS).

- Problem Areas and Action Taken. None.

- Milestone Status.

- April 30, 1995. Westinghouse Hanford Company completes installation of two of seven instrument trees in assumed leaker ferrocyanide tanks (Tri-Party Agreement Milestone M-40-02B). The second of these seven trees was installed in March 1995 in tank 241-TY-104 after auger sampling was completed in the shallow-depth tank. Both this tree and the one installed in tank 241-T-107 in November 1994 are scheduled to be connected to TMACS in early April 1995. 
- September 30, 1995. Westinghouse Hanford Company completes installation of remaining five instrument trees in assumed leaker ferrocyanide tanks (Tri-Party Agreement Milestone M-40-02). This milestone will be complete when all.five instrument trees are connected to TMACS. The milestone also closes out DNFSB Recommendation 90-7.1.

\subsubsection{Upgrades to Existing Temperature Monitoring Instrumentation}

This task determined the operability and accuracy of previously installed TC elements in the original 24 Ferrocyanide Watch List tanks. The original and newly installed instrument trees provide temperature measurements for the ferrocyanide tanks.

Field measurements were taken in 1991 on each TC element in the then-existing trees to determine the resistance and voltage across the junction and across each lead to ground. . The exact condition of each TC element was determined by resistance and voltage measurements (Bussell 1992). This work was completed in FY 1991 with a total of 265 TC elements being evaluated. Work in FY 1992 focused on repair and recovery of 92 TC elements that were found to be failed or marginal in performance. This task was completed in FY 1992.

- Progress During Reporting Period. No progress was required or planned.

- Planned Work for Subsequent Months. None.

- Problem Areas and Actions Taken. None.

- Milestone Status. This task is complete.

\subsubsection{Hot Spot Thermal Modeling}

Radioactive materials decaying in Hanford Site waste tanks generate heat. An early concern, raised when the ferrocyanide tanks first became a safety issue, was whether an exothermic excursion and local propagation could occur within the ferrocyanide waste if a sufficient concentration of ferrocyanide and a high enough temperature were present. This task examined the available temperature data from the ferrocyanide tanks in order to determine the heat load and temperatures as a function of depth and radial location. Sensitivity and parametric analyses were included to determine the magnitude of a hot spot that would have to exist for the waste to reach propagation temperatures.

Heat load analyses and thermal characteristics were completed for all ferrocyanide tanks in FY 1994 (McLaren 1994a, 1994b). The maximum heat load of any ferrocyanide tank, assuming worst-case conditions for soil moisture and thermal conductivity, was below 4.2 kilowatts $(\mathrm{kW})$. Nominal heat loads calculated by McLaren (1994a, 1994b) compared . very favorably with those calculated independently in 1993 (Crowe et al. 1993). A dryout 
analysis was also completed and released in FY 1994 (Epstein et al. 1994). The report concluded that ferrocyanide sludge could not dry sufficiently to be chemically reactive during interim storage, either globally or locally. Dryout mechanisms evaluated included global evaporation, removal of liquid by leakage or pumping, boiling as a result of hot spots, and enhanced surface evaporation from hot spots. All activities were completed for this task in FY 1994.

- Progress During the Reporting Period. None.

- Planned Work for Subsequent Months. None.

- Problem Areas and Action Taken. None.

- Milestone Status. This task is complete.

\subsubsection{Infrared Scanning System}

Infrared (IR) scanning systems are commercially available from numerous vendors. These systems are sensitive to changes of $\pm 0.3^{\circ} \mathrm{C}$ or less under ideal conditions and offer promise for mapping surface temperature profiles in the ferrocyanide tanks. Thermal modeling performed on ferrocyanide tank 241-BY-104 (McLaren 1993) suggested that if hot spots with temperatures of concern are possible, surface temperature differences might be great enough to be detected by IR mapping.

A position paper on the credibility of hot spots and the need for further IR scanning was issued in April 1993 (Dickinson et al. 1993). Further analyses have been performed to assess potential dryout of the ferrocyanide waste (Epstein et al. 1994). These reports examined potential mechanisms for forming hot spots. Analyses indicate that hot spots are not credible in ferrocyanide tanks. Based on these analyses, Westinghouse Hanford Company recommended that no further planning be pursued for IR scans for the purpose of detecting hot spots.

- Progress During the Reporting Period. None.

- Planned Work for Subsequent Months. None.

- Problem Areas and Action Taken. None.

- Milestone Status. This task is complete. 


\subsection{CONTINUOUS TEMPERATURE MONITORING}

"The temperature sensors referred to above [Recommendation 90-7.1] should have continuous recorded readouts and alarms that would signal at a permanently manned location any abnormally high temperatures and any failed temperature instrumentation."

This task provides continuous monitoring of presently installed (and operable) temperaturesensing elements for the ferrocyanide tanks. New instrument trees will be connected to the system as they are installed into each tank, resulting in continuous temperature monitoring in the ferrocyanide tanks. All data are collected automatically at the continuously manned Computer Automated Surveillance System (CASS) Operator Control Station. The monitoring system is independent of the.CASS and capable of displaying data to an operator on request. Trend data on selected points are available for display in numeric or graphic form.

The system, which became operational in September 1991, has the capacity to assign alarms for a change in the value of any temperature point. Alarms, if they occur, trigger an audible annunciator and are logged immediately to hard copy. An alarm summary display provides a list of the most recent alarms in order of occurrence. Each alarm can be identified by point and time of occurrence. Operator acknowledgement of the alarm will silence the audible annunciator. Signal conditioning and multiplexing are performed locally at each tank, eliminating the need to transmit low-level signals to the tank farm boundary and reducing cable runs. Electronic noise, extension wire corrosion, and thermal gradients are also reduced.

- Progress During Reporting Period. At least one instrument tree in each of the 18 ferrocyanide tanks is connected to TMACS for temperature monitoring. Twenty-three instrument trees in the 18 ferrocyanide tanks are now being monitored continuously by TMACS. Four newly-installed instrument trees remain to be connected to TMACS. Two of these trees in tanks 241-T-107 and 241-TY-104 will be connected in April to meet Tri-Party Agreement Milestone M-40-02B (see Section 3.1.1). The TMACS installation design was completed last fiscal year for these new trees.

- Planned Work For Subsequent Months. Connection of new instrument trees to TMACS will be made as soon as practical after the trees are installed. Next quarter, trees in tanks 241-T-107, 241-TY-104, 241-BY-107, and 241-TX-118 will be connected to TMACS for continuous monitoring. Each of these tanks contains an older tree that is already being monitored continuously by TMACS.

- Problem Areas and Action Taken. None. 
- Milestone Status.

- September 30, 1995. Westinghouse Hanford Company completes TMACS connections for all installed instrument trees in ferrocyanide tanks. This milestone completes Tri-Party Agreement Milestone M-40-02 and also closes out DNFSB Recommendation 90-7.2.

\subsection{COVER GAS MODELING}

"Instrumentation should also be installed to monitor the composition of cover gas in the tanks, to establish if flammable gas is present."

\subsubsection{Interim Flammable Gas Monitoring}

The effort to conduct flammable and toxic gas monitoring and analyses in the ferrocyanide tanks is continuing. Most of this effort was transferred to the Tank Vapor Monitoring Program, which is coordinating interim gas monitoring of the ferrocyanide tanks, as well as those tanks involved with the tank vapor program. Tank dome spaces are measured for flammability using a commercial combustible gas monitor (calibrated with pentane gas), and are monitored for potential toxic gases using an organic vapor monitor and Dräger ${ }^{3}$ tubes. Development and validation of alternative technologies for dome space characterization are in progress using sorbent tubes placed on the end of tubes lowered into the dome space and SUMMA 4 canisters that collect gas samples topside. The initial dome space sampling was done in several tank locations (i.e., from two widely separated risers) and at three elevations in the dome space. Reviews of sampling data and modeling (Wood 1992, Claybrook and Wood 1994, Postma et al. 1994b) indicate that the vapor space is well mixed and that sampling from one riser at one elevation is adequate.

- Progress During Reporting Period. Vapor samples were taken from only one ferrocyanide tank this quarter, 241-T-107, using the heated tube Vapor Sampling System (VSS). Analyses reports for this tank show 125 ppmv of ammonia, 42 ppmv of $\mathrm{N}_{2} \mathrm{O}$, and $1.4 \mathrm{mg} / \mathrm{m}^{3}$ of total non-methane organic compounds. The combined value for $\mathrm{NO}+\mathrm{NO}_{2}$ was less than $0.1 \mathrm{ppmv}$. Reports were received from the various laboratories that have been contracted to analyze tank headspace gas samples. The reported results have been incorporated into Table A-2 of Appendix A. This table lists vapor sampling results available as of March 31, 1995.

\footnotetext{
${ }^{3}$ Trademark of Drägerwerk Aktiengesellschaft, Inc., Lubeck, Germany; also National Draeger, Inc., Pittsburgh, Pennsylvania.

${ }^{4}$ Trademark of Molectrics, Inc., Cleveland, Ohio.
} 
The ammonia concentration reported in the dome space of tank 241-T-107 was 125 ppmv, which is higher than the National Institute of Occupational Safety and Health (NIOSH) 8-hr recommended exposure limit of 25 ppmv (NIOSH 1995). Ammonia concentrations for other ferrocyanide tanks have ranged from a low of $2.7 \mathrm{ppmv}$ (tank 241-C-108 to a high of 1040 ppmv (tank 241-BY-108). The $\mathrm{NO}_{2}$ concentration in 241-T-107 was reported as 42 ppmv: Other ferrocyanide tanks have ranged from 16.5 ppmv (tank 241-BY-103) to 641 ppmv (tank 241-BY-108) using the VSS method. A hydrogen concentration for tank 241-T-107 was not reported. Hydrogen concentrations for the ferrocyanide tanks have all been lower than about $400 \mathrm{ppmv}$ using the VSS method.

All 18 tanks on the Ferrocyanide Watch List have been vapor sampled, but not all have been sampled by the VSS using the heated sampling tubes. The three 241-TY tanks are the last tanks to be sampled by this method; all are scheduled for VSS sampling in April 1995.

- Planned Work For Subsequent Months. Ferrocyanide tank headspace gas sampling using the VSS method will be completed next quarter. Repeat sampling will continue on a periodic basis as part of the Tank Vapor Monitoring Program. Tank sampling using the combustible gas monitor, the organic vapor monitor, and Dräger tubes is required each time a riser is opened.

- Problem Areas and Actions Taken. None.

- Milestone Status

- September 30, 1995. Westinghouse Hanford Company completes dome space sampling of remaining ferrocyanide tanks. Completion of this milestone closes out DNFSB Recommendation 90-7.3. This milestone also addresses the Tri-Party Agreement Milestone M-40-03 to complete headspace characterization of all Ferrocyanide Watch List tanks by November 30, 1995.

\subsubsection{Continuous Gas Monitoring}

The possibility that localized concentrations or stratification of gases exist in the tanks has been evaluated. A modeling study to determine airflow patterns in the dome space of tank 241-C-109 was conducted to evaluate the amount of mixing and the local gas concentrations that could occur. The study revealed that the gases in the tank are well mixed and follow Graham's law for gaseous diffusion; therefore, an analysis of a second tank was considered unnecessary (Wood 1992). Studies completed since that time (Claybrook and Wood 1994, Postma et al. 1994b) also confirm that conclusion. 
The need for continuous gas monitoring was addressed in a report that also assessed the potential for cyclic venting and the possibility of accumulating flammable gases (Fowler and Graves 1994). The report concluded that continuous flammable gas monitoring in ferrocyanide tanks is not warranted based on: (1) the low concentration of flammable gases found to date; (2) anticipated low ferrocyanide concentrations because of waste aging; (3) analytical results from tanks 241-C-109 and -112 showing that the fuel concentration in the tanks is much lower than postulated by flowsheet values and operating records; and (4) calculations of hydrogen accumulation using realistic generation values and passive ventilation assumptions. No further activities are planned in this task.

- Progress During Reporting Period. None.

- Planned Work For Subsequent Months. This task is complete. DOE has concurred that no continuous gas monitoring is required (O'Leary 1994).

- Problem Areas and Actions Taken. None.

- Milestone Status. None

\subsection{FERROCYANIDE WASTE CHARACTERIZATION}

"The program of sampling the contents of these tanks should be greatly accelerated. The proposed schedule whereby analysis of two core samples from each single-shell tank is to be completed by September 1998 is seriously inadequate in light of the uncertainties as to safety of these tanks. Furthermore, additional samples are required at several radii and at a range of elevations for the tanks containing substantial amounts of ferrocyanide."

Characterization of the waste in the ferrocyanide tanks is necessary to: (1) guide further chemical reaction studies with the ferrocyanide waste simulants; (2) determine actual waste chemical and physical properties; (3) determine how the ferrocyanide waste can be safely stored in situ, and the tanks classified by safety category accordingly, until retrieval and disposal actions are completed; and (4) apply the study results to the final remediation of the waste. This information is necessary to resolve the Ferrocyanide Safety Issue.

The important reactive materials present in the ferrocyanide tanks are fuel (ferrocyanides, sulfides, and reduced carbon species such as organic complexants), oxidants (nitrates and nitrites), and inerts or diluents (including phosphates, aluminates, sulfates, carbonates, oxides, and hydroxides). The location of fission products such as ${ }^{137} \mathrm{Cs}$ and ${ }^{90} \mathrm{Sr}$ is important because these products are heat sources and potential source terms in postulated radiological releases from a hypothetical ferrocyanide reaction. The water content of the waste is very important because water's high heat capacity and heat of vaporization make it an effective inerting material. Water can prevent a sustained combustion or a propagating reaction; wet ferrocyanide material would require drying before it could react or propagate. 


\subsubsection{Ferrocyanide Tank Waste Sampling and Analyses}

Tank Sampling. Rotary-mode and push-mode sampling capabilities and auger surface sampling are used to obtain waste samples from the Watch List tanks. Tanks without saltcake and with relatively soft waste solids can be sampled by the push-mode method. If a hard saltcake layer is present, rotary-mode sampling can be used. Auger sampling may also be used if the depth of waste is nominally less than $60 \mathrm{~cm}$.

Each core consists of several 48-cm segments (or portions thereof) depending on the depth of the waste in the tank. The sludge layer in these cores will be divided into four 12-cm subsegments for each $48-\mathrm{cm}$ segment. If the tank contains a saltcake layer, the saltcake segments will be divided into only two subsegments. Process flowsheet knowledge, tank historical data, and results obtained from tests with ferrocyanide sludge simulants are used to supplement the analytical results from core sampling.

The priority for sampling ferrocyanide tanks has been changed to reflect the need to determine the reactive properties of the contents. In response to DNFSB Recommendation 93-5 (DOE 1994a) to expedite sampling and analyses required to address safety issues in the Hanford Site Watch List tanks, the analysis plans for future ferrocyanide tank core samples (and the plans for other Watch List tanks) have been revised. The Watch List tanks have been given priority for core sampling, and the number of required analytes was reduced. Analyte selection was refocused primarily on safety-related properties.

- Progress During Reporting Period. The first ferrocyanide tank to be rotary-mode sampled was 241-BY-106, which was attempted in November 1994. Volume recovery for the core was mixed, ranging from near zero to almost $100 \%$ for the 13 segments. A decision was made this quarter not to attempt sampling in a second riser until modifications to the truck are made and better recovery is possible. Meanwhile, the truck has been deployed to take push-mode samples.

Preliminary analytical results are available for the small amount of sludge $(\sim 5 \mathrm{~cm})$ that was recovered from the 241-BY-106 rotary-mode core sample. The sample contained significant moisture (37 wt\%); however, notable exothermic energy was measured by differential scanning calorimetry (DSC). Three DSC analyses on the sludge material measured $670,1,400$, and $670 \mathrm{~J} / \mathrm{g}$ on a dry basis, about the values anticipated for ferrocyanide sludge if no aging had occurred. However, waste transfer records indicate that tank 241-BY-106 also received significant ( $>3 \mathrm{wt} \%$ ) quantities of organic material (Toth et al. 1995). Therefore, the exothermic energy may be a result of organic compounds in the sludge. Analyses for total organic carbon, total cyanide, and nickel concentrations are currently being conducted to determine the source of the exotherm.

Auger sampling was completed for two ferrocyanide tanks this quarter, 241-C-111 and 241-TY-104. Recoveries for the two augers from tank 241-C-111 were 33\% (riser 7) and $100 \%$ (riser 4). The top quarter segment (A) contained two distinct 
phases, a top salt-like crust material and a more sludge- like material. The quarter segment was further broken down into two samples (A1 and A2); however, some mixing of the two phases did occur during extrusion and sample breakdown. Recoveries for the two augers from tank 241-TY-104 were 67\% (riser 18) and $100 \%$ (riser 15).

Safety screening analyses on samples taken from tanks 241-C-108 and 241-TY-104 were completed this quarter (WHC 1995a and 1995b) and the results are summarized in Tables 3-1 and 3-2, respectively. The samples showed high moisture concentration and negligible exothermic energy except for the sample taken from riser 7 in tank 241-C-108. The top quarter segment revealed low moisture (and no exothermic energy); however, this quarter segment was not representative of typical ferrocyanide sludge. Quarter segments B and C from this same riser had exotherms of 43 and $109 \mathrm{~J} / \mathrm{g}$, respectively, on a dry weight basis. These values are far below the $1,200 \mathrm{~J} / \mathrm{g}$ required to sustain a propagating reaction (Fauske 1995).

Table 3-1. Analyses of Auger Samples From Tank 241-C-108.

\begin{tabular}{|l|c|c|}
\hline \multicolumn{1}{|c|}{ Sample Location } & $\begin{array}{c}\text { DSC Results } \\
\text { (J/g-dry basis) }\end{array}$ & $\begin{array}{c}\text { Moisture } \\
\text { (wt\%) }\end{array}$ \\
\hline Riser 7, 1/4 Segment A1 & 0 & 9.2 \\
\hline Riser 7, 1/4 Segment A2 & 0 & 19 \\
\hline Riser 7, 1/4 Segment B & 43 & 36 \\
\hline Riser 7, 1/4 Segment C & 109 & 46 \\
\hline Riser 4, 1/4 Segment A & 0 & 49 \\
\hline Riser 4, 1/4 Segment B & 0 & 50 \\
\hline Riser 4, 1/4 Segment C & 0 & 53 \\
\hline Riser 4, 1/4 Segment D & 0 & 49 \\
\hline
\end{tabular}

Table 3-2. Analyses of Auger Samples From Tank 241-TY-104.

\begin{tabular}{|l|c|c|}
\hline \multicolumn{1}{|c|}{ Sample Location } & $\begin{array}{c}\text { DSC Results } \\
\text { (J/g-dry basis) }\end{array}$ & $\begin{array}{c}\text { Moisture } \\
\text { (wt\%) }\end{array}$ \\
\hline Riser 15, 1/4 Segment D & 0 & 52 \\
\hline Riser 18, 1/4 Segment C & 0 & 52 \\
\hline Riser 18, 1/4 Segment D & 0 & 52 \\
\hline
\end{tabular}


- Planned Work For Subsequent Months. Screening analyses will be completed for the auger samples taken from tank 241-C-111 next quarter. The ferrocyanide tanks scheduled for core sampling (in sequence) are 241-BY-108, -BY-110, -BY-103, -BY-104, -BY-106, -BY-105, and -TY-103. Push-mode core sampling may be attempted in some of these tanks to expedite the sampling schedule.

- Problem Areas and Actions Taken. Rotary-mode sampling of fẹrrocyanide tank 241-BY-106 encountered varying degrees of segment recovery. The rotary-mode sampler, different sampling bits, and improved procedures are currently being tested to improve core recovery performance. Lessons learned from testing and from an indepth technical review of the rotary mode sampling truck will be applied to future core sampling. Core sampling from the second riser (No. 5) of tank 241-BY-106 will not be attempted until better recoveries are achieved.

\section{- Milestone Status.}

- October 31, 1994. Westinghouse Hanford Company secures rotary-core samples from ferrocyanide tank 241-BY-106. Thirteen core segments were attempted in this tank from one of two risers to be sampled. A second attempt was also made in the same riser. Sampling from a second riser will not be started until better segment recoveries are demonstrated.

- June 30, 1995. Westinghouse Hanford Company obtains core and/or auger samples from four ferrocyanide tanks. Two full-depth auger samples have been obtained from tanks 241-C-108, -C-111, and -TY-104 thus far. This milestone remains on schedule.

- September 30, 1995. Westinghouse Hanford Company completes data interpretation reports, available for public release, for four ferrocyanide tanks. Forty-five day screening analyses reports have been completed for tanks 241-C-108 and -TY-104 (WHC 1995a and 1995b). This milestone remains on schedule.

- December 31, 1995. Westinghouse Hanford Company obtains core samples from five additional ferrocyanide tanks.

- March 31, 1996. Westinghouse Hanford Company completes data interpretation reports, available for public release, for five ferrocyanide tanks.

- July 31, 1996. Westinghouse Hanford Company obtains core samples from the remaining ferrocyanide tanks. 
- October 31, 1996. Westinghouse Hanford Company completes data interpretation reports, available for public release, for the remaining ferrocyanide tanks. Westinghouse Hanford Company secures rotary-mode samples from ferrocyanide tank 241-BY-106. Thirteen core segments were attempted in this tank from one of two risers to be sampled. Sampling from the second riser will not be started until better segment recoveries are demonstrated by repeat sampling in the first riser or in another tank.

Infrared Spectroscopy Analyses. Near infrared (NIR) spectroscopy is one of the commercially available techniques being used for demanding applications such as in situ and remote characterization of highly toxic and hazardous materials. The biggest challenges are related to the specific sensitivities with tank waste materials and the engineering required to implement the technology in hot cell and waste tank applications. Although the infrared spectra of samples containing water is normally dominated by the strong absorption from the water molecules, there are spectral windows where spectra from other molecular species are usable. As such, NIR spectroscopy is also being considered as a direct technology for moisture sensing. In addition, sample preparation methods such as freeze drying may be possible with tank materials.

In general, tank wastes exhibit strong optical scattering and absorption. As indicated in Figure 3-1, tank simulants are typically optically dark (which suggests high optical absorption) with some color variations between different simulants. This darkness also shows that moisture content within a simulant also strongly impacts the opacity of the sample, suggesting that visual methods to assess chemical boundaries would be falsely biased by water content.

The absorption from water and other species is strong enough that light backscattered from a surface can be used to sense their presence. A method to use NIR backscatter is being pursued in which water content is derived from numerical analysis of spectra using a partial least squared (PLS) calibration model with baseline-corrected spectral data.

Recent developments in Fourier Transform Infrared (FTIR)-based fiber optic (FO) spectroscopy have also opened the potential for remote characterization of tank waste materials. The feasibility of FTIR in glovebox environments is being pursued with pure, simulant, and actual tank waste materials. The FTIR-FO method offers direct, rapid, and nondestructive measurement of infrared-active organic and inorganic species in the waste.

- Progress During Reporting Period. Cold calibration testing was completed using four waste simulants having a moisture content ranging from 0 to $60 \mathrm{wt} \%$ and the NIR spectroscopy system developed by Savannah River Laboratory. The results of the NIR cold test and demonstration work were summarized in a report by Reich et al. (1995). 
Figure 3-1. Photograph of Four Tank Waste Simulants Showing Color

Variations Among Samples as a Function of Weight Percent Moisture.

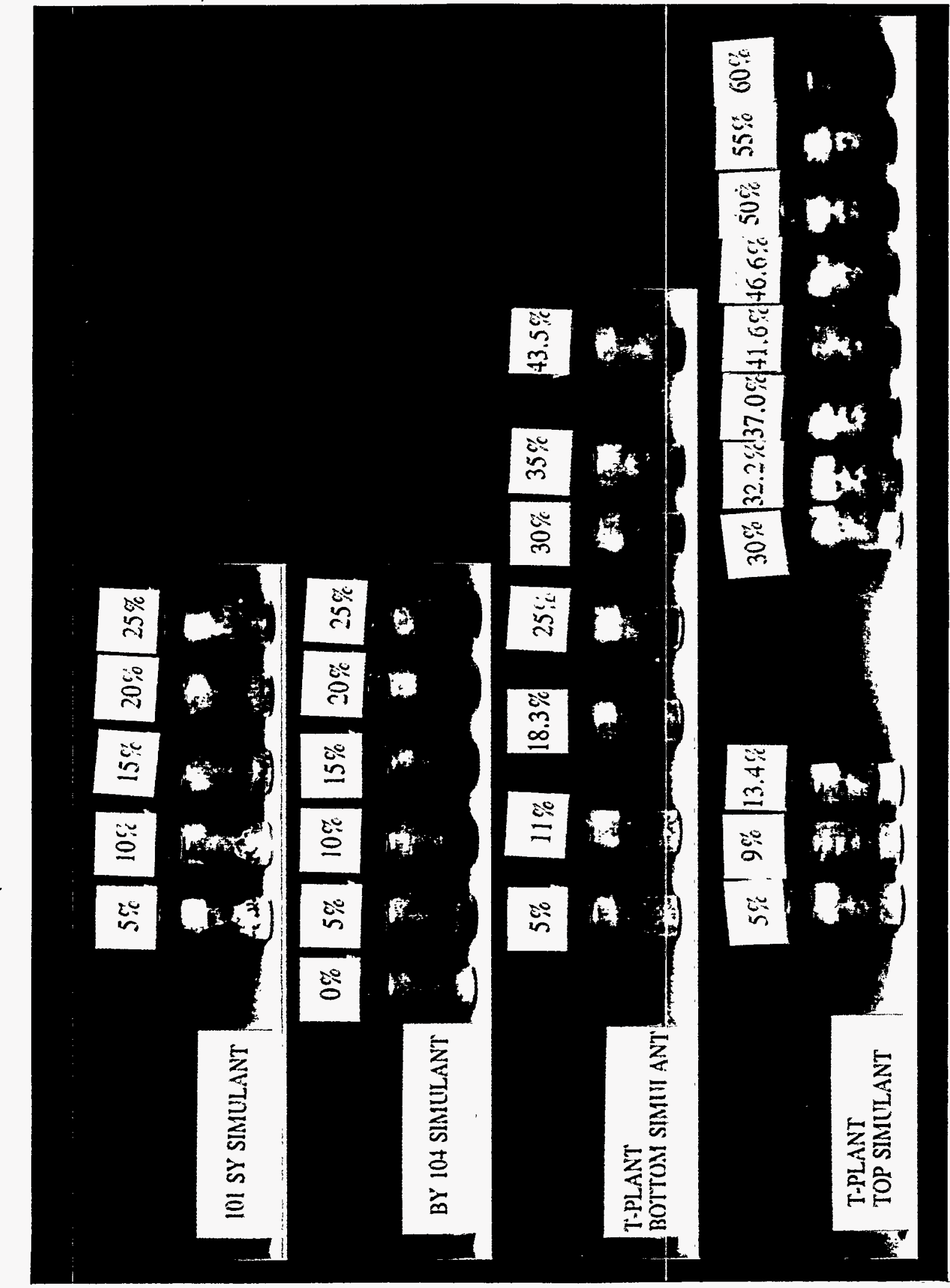


The results of a calibration test with four tank simulant materials having moisture contents ranging from 0 to $60 \mathrm{wt} \%$ were evaluated. The simulants and moisture ranges used in this testing were: 101-SY (complexed waste simulant containing organics), 5 to $25 \mathrm{wt} \%$ moisture; BY-104 (saltcake simulant), 0 to $25 \mathrm{wt} \%$ moisture; T-Plant bottom ferrocyanide simulant, 5 to $40 \mathrm{wt} \%$ moisture; and T-Plant Top ferrocyanide simulant, 10 to $60 \mathrm{wt} \%$ moisture. The NIR system with a PLS model demonstrates that the moisture content was determined to within $\pm 5 \mathrm{wt} \%$ for all of the four simulants over the 0 to $60 \mathrm{wt} \%$ range. Five-factor PLS models for each specific simulant demonstrated an even better prediction error ( \pm 2 to $3 w t \%$ ).

Work on the speciation of IR-active components and moisture sensing is being conducted with archived tank waste samples at the 222-S Laboratory. Four waste samples obtained by sampling SSTs (two ferrocyanide tanks and two organic tanks) were screened for their chemical functionality. Two-gram aliquot samples from tanks 241-BY-108 (saltcake only), 241-C-108, 241-C-102, and 241-C-103 (all sludge tanks) were placed in small stainless steel planchets and examined with NIR radiation. The spectral results are shown in Figures 3-2 and 3-3.

The spectra from these tank waste samples (Figure 3-2) confirm the strong moisture dependence of the waste's spectra. Of specific interest is the fact that even though some of these waste samples had low moisture contents ( $<15 \mathrm{wt} \%)$, they still exhibit spectral structures characterized by the presence of sharp, moderately intense bands superimposed on a sloping background in the region where the first overtone of the $\mathrm{OH}$-stretch band $\left(7,200 \mathrm{~cm}^{-1}\right.$ to $\left.6,400 \mathrm{~cm}^{-1}\right)$ occurs. As the moisture content increases ( $>15 \mathrm{wt} \%$ ), these bands disappear because of the overlap of the more intense but broader $\mathrm{OH}$-stretch band of free water $\left(6,900 \mathrm{~cm}^{-1}\right)$, showing that if the samples' moisture content is low, it may be possible to sense the presence of other molecular species, particularly organic compounds.

Figure 3-3 displays the expansion of the spectra of an aliquot of 241-BY-108 saltcake containing $4 \mathrm{wt} \%$ water. These spectra demonstrate the potential to detect the presence of other tank species when the waste water content is low. The top spectrum represents the region of high wave numbers $\left(7,200 \mathrm{~cm}^{-1}\right.$ to $\left.6,400 \mathrm{~cm}^{-1}\right)$ associated with the first overtones of the $\mathrm{OH}^{-}, \mathrm{NH}^{-}$, and $\mathrm{NH}_{2}^{-}$bands. The first five bands may be due to the first overtones of the $\mathrm{OH}^{-}$vibration of hydrates of calcium phosphate and calcium sulfate as well as the hydrous oxides of aluminum and iron. Two weak bands appearing at $6,586 \mathrm{~cm}^{-1}$ and $6,482 \mathrm{~cm}^{-1}$ can also be discerned. It is speculated that these bands may be caused by the asymmetric and symmetric stretching vibration of the $\mathrm{NH}^{=}$and $\mathrm{NH}_{2}^{-}$functions of ethylenediamine tetraacetic acid salts and/or their decomposition products. 
Figure 3-2. Spectra of Waste Samples From Tanks BY-108, C-102, C-103, and C-108.
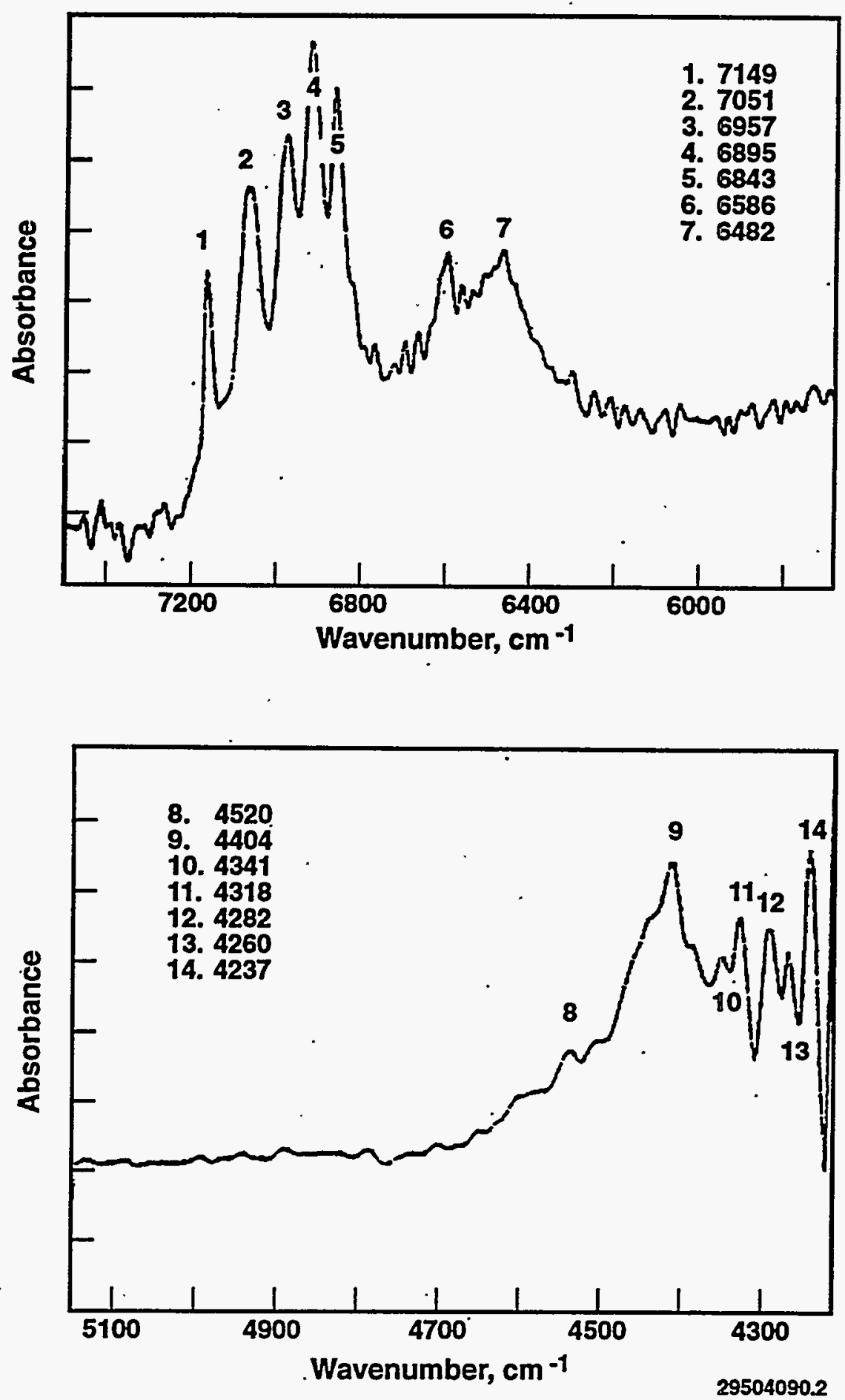
Figure 3-3. Expanded Spectra for Tank BY-108 Saltcake Waste Containing 4 wt\% Moisture.
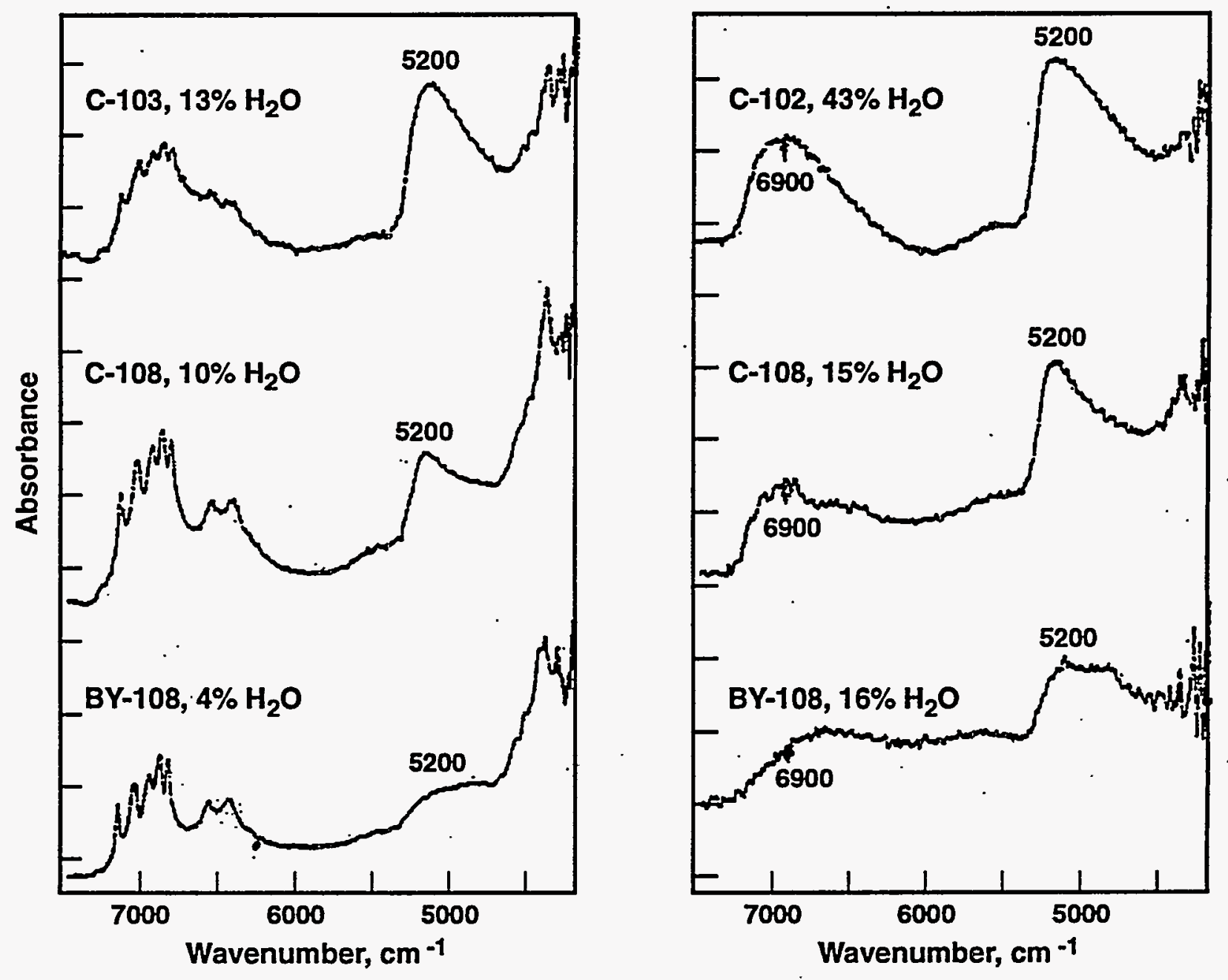

29504090.1 
- Planned Work For Subsequent Months. Installation of a modular transfer optic system will be completed. FTIR-FO screening of waste sludge and saltcake samples for moisture and for ferrocyanide and organic species will continue as samples become available from the SSTs.

Technology transfer of infrared photoacoustic spectroscopic methods to Westinghouse Hanford Company will resume next quarter when a scientist from the DOE Ames Laboratory in Ames, Iowa, visits the Hanford Site to conduct analyses of tank waste samples.

- Problem Areas and Actions Taken. None.

- Milestone Status.

- September 30, 1995. Westinghouse Hanford Company issues a final report on FTIR technology development for determination of moisture and for ferrocyanide and organic species in tank waste samples.

Mössbauer Spectroscopy. A small task on Mössbauer spectroscopy is investigating the physical and chemical nature of iron within ferrocyanide tank waste. The National Aeronautics and Space Administration (NASA) has developed a miniaturized Mössbauer spectrometer that is small enough to perform elevation scans in the LOWs. Iron is a major constituent of ferrocyanide waste and information about its location and composition in the tanks supports safe interim storage and eventual retrieval of the waste.

Mössbauer spectroscopy can provide the valence state of iron as well as specific coordination chemistry for the iron atom. That is, Mössbauer spectroscopy can see differences in anions surrounding the iron cation in a stable crystalline structure and distinguish between different iron-based minerals. A recent development in this type of spectroscopy is the use of reflectance rather than transmission spectroscopy, thus allowing information to be gained in situ rather than having to use waste samples from the tanks. Mössbauer spectroscopy can distinguish between ferrocyanide and ferricyanide complexes and almost any iron compound that might exist within tank waste. By knowing the iron concentration and species as a function of elevation in a given tank, it should be possible to determine how much aging has occurred within the waste.

The Mössbauer program represents a cooperative venture between Westinghouse Hanford Company, DOE, and NASA. The contact at NASA is Dr. Richard Morris at the Johnson Space Center in Houston, Texas.

- Progress During Reporting Period. The scientist responsible for the Mössbauer program at Westinghouse Hanford Company met with Dr. Morris in Houston this quarter. U-Plant simulant was tested using the NASA Mössbauer spectrometer. Spectra obtained by Dr. Morris for this ferrocyanide waste simulant were discussed. Iron (II) shows up in all the spectra, and the presence of small amounts of Iron (III) 
was also discernable. NASA has found that the relative magnitudes of these two iron valence states can be determined by careful analysis of the spectra. Reflectance spectra obtained from a separate high-resolution spectrophotometer confirm the Mössbauer results.

The electronic circuit for the portable spectrometer was redesigned by NASA and the new probe has significantly less noise than the previous version. Data were collected on the old probe to make certain that it was functioning correctly.

- Planned Work for Subsequent Months. A contract between Westinghouse Hanford Company and NASA for procurement of a miniature spectrometer for use at the Hanford Site will be placed next quarter.

Arrangements are underway to conduct a hot cell test in July 1995 using waste from a ferrocyanide tank. One of the 241-BY farm tanks that contains a LOW will be selected to do the initial scan using the new Mössbauer spectrometer to be acquired from NASA. A sample of LOW material will be sent to Dr. Morris of NASA for tests to determine its iron content and if any interferences might exist.

- Problem Areas and Actions Taken. Because of other commitments, Dr. Morris will not be available for a visit to the Hanford Site during April 1995. Therefore, the hot cell test has been postponed until July 1995. Actual scans in the LOW of a ferrocyanide tank may now slip to September 1995.

- Milestone Status.

- April 30, 1995. Westinghouse Hanford Company initiates hot cell testing of the Mössbauer tank probe using ferrocyanide tank waste samples. This test is expected to slip by one month.

- July 31, 1995. Westinghouse Hanford Company completes an in-tank test of the Mössbauer probe in a LOW in one of the ferrocyanide tanks. This milestone may slip to early September 1995.

- September 30, 1995. Westinghouse Hanford Company issues a report, available for public distribution, on the Mössbauer spectroscopy program results for FY 1995.

Scanning Electron Microscopy. Chemical and physical properties of ferrocyanide, tank waste are being obtained to accurately assess the waste for safety and inventory purposes. Analyses indicating the presence or absence of key chemical components-including $\mathrm{CN}^{-}, \mathrm{Na}, \mathrm{Fe}, \mathrm{Ni}$, and $\mathrm{Cs}-$-can be used to characterize the tank waste and to assess whether the waste can be stored safely until retrieved for final disposal. Measurements that allow examination of possible correlations of chemical composition and physical properties, 
such as particle and crystallite size, may provide additional information on how the waste has degraded with time and to compare real waste properties with those obtained earlier from waste simulants.

Scanning Electron Microscopy (SEM), coupled with backscattered electron detection and energy dispersive X-ray spectroscopy, provides a method uniquely capable of providing particle size, chemical composition, and particle morphology information in a single measurement. Recent developments in instrumentation computer control, digital data acquisition, and light element $\mathrm{X}$-ray detection have significantly enhanced the utility of these technologies for particle characterization applications. Refinements in software allow rapid collection, processing, and storage of large volumes of chemical and numerical data. These enhancements to the instrumentation provide a new and potentially powerful methodology for the characterization of ferrocyanide and organic tank waste.

- Progress During Reporting Period. Procurement of a computer-controlled SEM (CCSEM) system from the R. J. Lee Group, Inc. was completed this quarter. The R. J. Lee Personal Scanning Electron Microscope (PSEM) 5 system and associated hardware and characterization software were inspected and tested at the vendor's Trafford, Pennsylvania facility during the week of January 30, 1995. The SEM system, specimen preparation equipment, and operational consumables were received on the Hanford Site on February 24, 1995.

Initial setup and installation of the PSEM ${ }^{\mathrm{TM}}$ system was completed the week of March 13, 1995. The SEM and associated computer and I/O) peripherals were set up in the $622 \mathrm{G}$ Building at the Hanford Site. Specimen preparation equipment to support the SEM was located in an adjacent trailer. The SEM systems will remain at these locations during the acceptance testing, method development, and simulant analysis phases of this activity.

All specified system SEM components were received in good order. During initial acceptance testing, non-acceptable performance was noted in the specimen stage subsystems, the image distortion correction sub-system, the disk I/O sub-system, and the magnification calibration. The problems were diagnosed with vendor representatives and resolutions defined.

- Planned Work For Subsequent Months. Repair or replacement of components or subsystems where sub-specification performance was noted during the initial PSEM ${ }^{\mathrm{TM}}$ installation will be completed by mid-April 1995 .

${ }^{5}$ PSEM is a registered trademark of the R. J. Lee Group, Inc., Trafford, Pennsylvania. 
Baseline and SEM performance monitor measurements will be completed. Initial test measurements and analyses of ferrocyanide tank waste simulants will be initiated in order to: (1) begin analytical protocol development for CCSEM analyses; and (2) finalize specimen form and preparation methods.

Activities will now be directed toward: (1) installation of the SEM system in a facility suitable for analysis of radioactive tank waste specimens; (2) finalization of sampling and specimen preparation protocols; and (3) definition of requirements for shipping and handling of radioactive and hazardous waste samples. Moving the CCSEM to a suitable facility is expected to occur in July 1995.

Procurement of SEM operational and specimen preparation consumables will be completed. Procurement of PSEM ${ }^{\mathrm{TM}}$ system upgrades will enhance ferrocyanide tank waste analyses.

- Problem Areas and Actions Taken. A facility suitable for SEM analysis of radioactive tank waste specimens has not been located. The PSEM ${ }^{\mathrm{TM}}$ system was temporarily located in the $622 \mathrm{G}$ Building at the Hanford Site until a final decision is made on a location capable of accommodating radioactive samples. The $622 \mathrm{G}$ facilities are sufficient to support CCSEM testing and method development activities using non-radioactive test materials and tank simulants. Discussions have been initiated with Westinghouse Hanford Company personnel in the 222-S Building for preparation of radioactive specimens for the SEM in or adjacent to the hot-cell facilities.

\section{- Milestone Status.}

- May 31, 1995. Westinghouse Hanford Company installs and completes operational acceptance tests on the CCSEM system. This milestone is expected to be completed in April 1995.

- September 29, 1995. Westinghouse Hanford Company issues a report, available for public release, on SEM program results for FY 1995.

\subsubsection{Estimation of Moisture Content}

Methods for determining moisture concentrations in ferrocyanide waste tanks are being developed using sample data analyses and available surveillance systems. This is an increase in scope from the original implementation plan (Cash 1991), which did not examine moisture monitoring. Two in situ moisture monitoring technologies are currently being investigated by the Ferrocyanide Safety Program: neutron diffusion and electromagnetic induction (EMI). Initial development of NIR spectroscopy was completed in FY 1994 at the University of Washington Center for Process Analytical Chemistry. This surface moisture monitoring technology will not be developed further by the Ferrocyanide Safety Program. Additional 
moisture monitoring technologies, such as copper foil activation and fission chamber in a cone penetrometer, are being evaluated by other programs. A report examining moisture monitoring technologies was completed in April 1993 (Meacham et al. 1993).

Neutron Diffusion. Well-logging techniques, coupled with computer modeling, were developed and applied to an existing neutron probe to determine information about moisture levels, material interfaces, and other waste characteristics in the ferrocyanide tanks. Using the knowledge gained from computer modeling, in situ measurements, and experimental calibration data with the current in-tank liquid level neutron probe (Watson 1993), prototype moisture measurement neutron probes were developed. This system consists of three neutron probes: a near-field thermal neutron probe, a far-field thermal neutron probe, and a far-field epithermal neutron probe. This improved system will be used primarily to determine the axial moisture concentration profile within the Ferrocyanide and Organic Watch List tanks.

Moisture measurement using neutron diffusion is an established technology. The technique uses a neutron source and one or more neutron detectors. The thermal neutrons reaching a detector originate as fast neutrons from the source and are slowed or absorbed by the medium. Because hydrogen atoms are effective at slowing down neutrons, the detector response is a strong function of the surrounding moisture concentration.

Two methods using neutron diffusion are generally used to measure moisture concentration around wells. The first method, the moisture gauge, has a short source-to-detector spacing (near field) on the order of 0 to $10 \mathrm{~cm}$. The response of a moisture gauge is characterized by an increase in detector response as the moisture concentration of the surrounding medium increases. The second method, the neutron $\log$, often has two detectors with longer source-to-detector spacings: 20 to $50 \mathrm{~cm}$ (far field). The detectors in a neutron log arrangement exhibit a decreased response to increased moisture concentrations. The detector placed at the shorter spacing is used to correct the response of the longer-spaced detector for borehole effects.

The tank moisture measurements are taken from within a LOW. The LOWs are permanently installed sealed pipes that extend from the riser top through the tank waste to near the tank bottom. The LOWs allow axial information about the surrounding waste materials to be obtained using certain detectors.

- Progress During Reporting Period. Calibrations of the prototype probes were performed using $15,20,25$, and 100 weight percent (wt\%) water simulants. These calibrations were completed in a simulant that contains many of the elements expected to be present in ferrocyanide sludge. Figure 3-4 shows the measured results compared with computer model predictions for the near-field thermal prototype probe. Good agreement has been achieved between the experimentally measured and computer modeled results; therefore, modeling efforts commenced this quarter to interpret moisture concentrations in the tanks where measurements have been obtained. Families of calibration curves will be generated for each probe type in response to several potential anomalies, so that the best interpretation of actual 
moisture concentration may be obtained. Temperature testing of the detectors and electronics was started in order to determine their sensitivities to temperature changes.

A computer code is being written to automatically read in the available data from moisture measurement probes and to provide a best-estimate moisture profile interpretation for each tank. The code will correlate the recorded data to the detector responses expected from different possible material anomalies and moisture contents. The code input will be based on computer modeling results of expected probe responses and on calibration data obtained from moisture standards.

Figure 3-4. Comparison of Measured and Model Predicted Responses of the Near-Field Thermal Neutron Probe to 15, 20, 25, and $100 \mathrm{wt} \%$ Water Simulant.

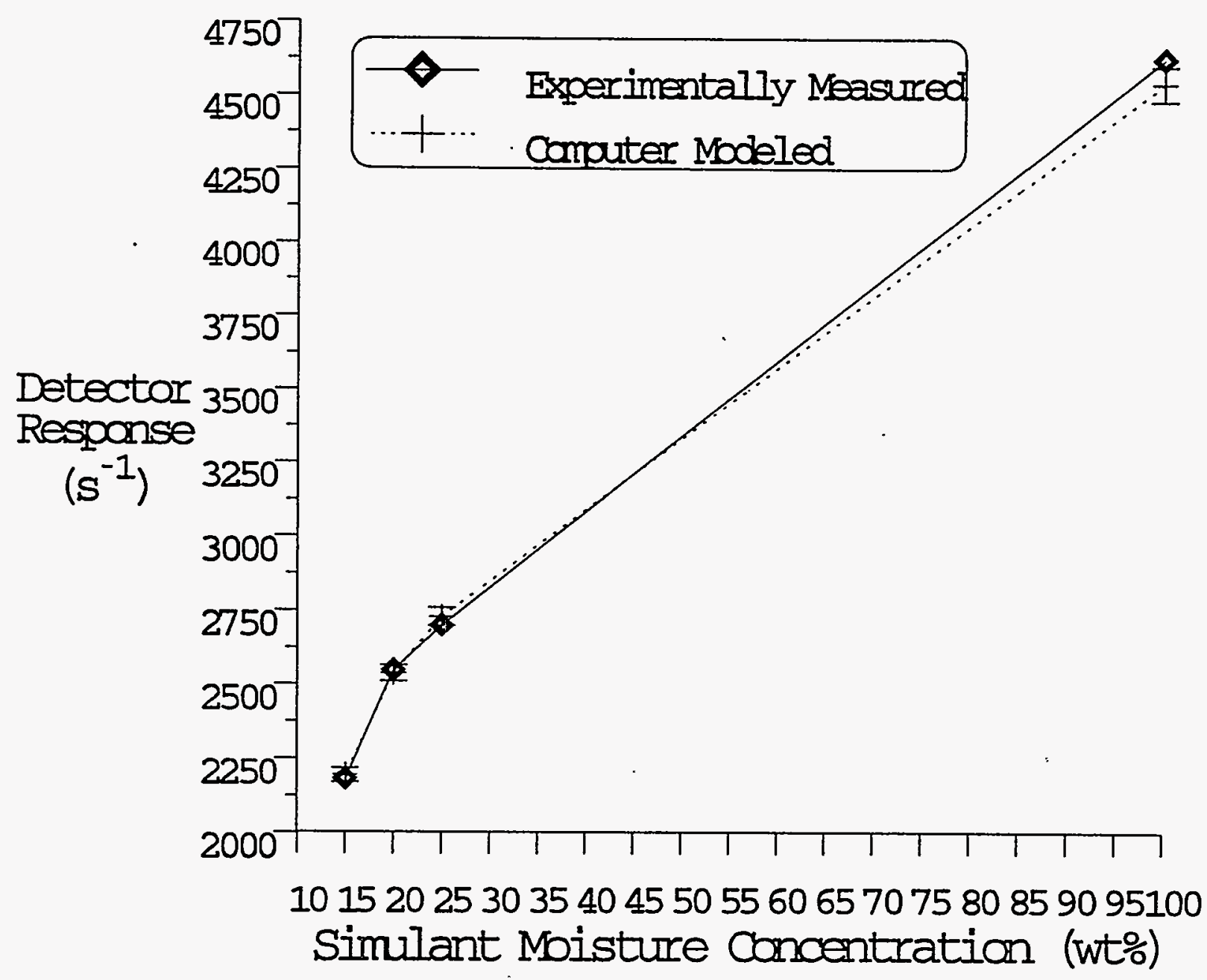


Based on computer modeling and test measurements using the prototype probes, two final field unit probes were designed; unit assembly was about $90 \%$ complete at the end of the quarter. One probe is designed to detect thermal neutrons and the other will detect epithermal neutrons. These field unit probes will each contain a near-field and a far-field detector. The design of these probes should increase the accuracy of the moisture determination in a high gamma field and will reduce required source handling and data collection times.

A potential neutron moisture probe for in-tank surface application is under investigation. Modeling results suggest that such a probe, lowered through a riser and placed in contact with the waste surface, would be quite sensitive to moisture concentrations to a depth of 10 to $20 \mathrm{~cm}$.

A new material and a new insertion method for LOWs are being developed to enhance probe responses to the moisture content of surrounding waste (Watson et al. 1994). Material constraints and practical considerations, coupled with computer modeling, have led to the selection of S-glass fiberglass composites as the LOW material that is being tested for suitability in the tank environment. This material contains no strong thermal neutron absorbers and will permit the application of moisture monitoring techniques based on electromagnetic induction. The new method of installation will use an ultrahigh-pressure water system as the bottom endplug of the LOW (Hertelendy 1993). This system will make the LOW self-inserting, will greatly reduce the water needed to insert the LOW, and will minimize generation of air- or liquid-filled cavities around the LOW. Installation of these new LOWs is anticipated to begin in FY 1996 to meet SST leak detection requirements and to support moisture concentration monitoring of Watch List tanks. The candidate LOW materials have undergone radiation, high temperature, and caustic chemical exposure testing to simulate a 20-year, worst-case tank environment. Samples of the materials are now being measured to assess the damage inflicted by these exposure tests. The interface connection between the fiberglass composite and the metal borehead is being tested.

- Planned Work for Subsequent Months. Results of the tank waste modeling task will assist with interpretation of data obtained from actual waste tank scans. A report will be issued providing the moisture interpretation results of these scans.

Development of an automated data moisture interpretation computer routine will continue.

Fabrication, testing, and calibration of two dual-detector, optimized field probes will be completed. Upgrades to an existing surveillance van are expected to begin so that the new dual-detector probes can be used in the tank LOWs. Tests of the new LOW material will be completed and the ultrahigh-pressure water system hardware will be 
acceptance tested. A new test fixture will also be constructed that will determine the responses of both the neutron and electromagnetic induction probes to potential air gaps between the LOW and the surrounding waste. The application of surface neutron moisture monitoring will be modeled and pursued for deployment in a tank.

- Problem Areas and Action Taken. As first discovered during in-tank tests using the existing liquid-level neutron probe, the boron content of the LOWs installed in the tanks is most likely different from that in the sample LOW section used for calibration (Watson 1993). Tank measurements have exhibited detector responses that, based on the experimental calibrations, do not appear to have any other explanation. The epithermal probe measurements seem to be unaffected by this phenomena. The measurements made in the riser/soil and riser/concrete dome region are being correlated with the model predictions in order to establish a LOW boron content that gives good agreement with the thermal neutron probe responses.

\section{- Milestone Status.}

- September 30, 1995: Complete installation and deployment of the first phase of the neutron moisture monitoring system and initiate monitoring. This milestone remains on schedule.

- September 30, 1996: Complete installation and deployment of the neutron moisture monitoring system for routine monitoring in ferrocyanide tanks.

Electromagnetic Induction Probe. The purpose of this task is to deploy the EMI probe in the LOWs and possibly on the waste surface in order to measure the waste moisture concentration in Ferrocyanide and Organic Watch List tanks. EMI probes operate by creating a magnetic field that induces current in a conductive medium. This induced current can be measured and is related to the media conductivity. The higher the electrical conductivity, the higher the free moisture content in the tank waste.

The EMI probe is designed with multiple separate coils of wire that can be either exciting coils or sensing coils. The exciting coil is driven with an electric current that creates a magnetic field. This magnetic field induces an electric current in conductive material, creating a secondary magnetic field that induces a voltage in the sensing coils. The intensity of the induced voltage in the sensing coils is directly related to the medium electrical conductivity. The electrical conductivity of tank waste is related to its free moisture content.

EMI (also called eddy current) inspection is a well-developed technology used in the nuclear, aviation, petroleum, and medical fields. The usual method of EMI inspection uses differential measurements or variations from a baseline signal. The measurement of conductivity is an absolute measure that requires careful attention to calibration. 
Two areas of engineering activity apply to EMI technology to the measurement of free moisture content in the high-level waste tanks: (1) EMI measurement of absolute conductivity of the waste medium; and (2) determination of the electrical conductivity as a function of the free moisture content of ferrocyanide or organic waste. Measurement of absolute conductivity will be studied using finite-element modeling of the EMI probe geometry. The modeling now being performed by Washington State University (WSU) will also aid in probe design and in interpretation of EMI-measured results.

The conductivity of ferrocyanide and organic waste as a function of moisture will be determined initially using representative simulants. The variability will be determined by drying each simulant to different moisture levels. It may be necessary to measure the conductivity of real waste samples if the composition of the waste is a dominant variable.

- Progress During Reporting Period. WSU has been performing finite element EMI probe simulations for the Westinghouse Hanford Company. Six different probe configurations have been modeled to date with several significant results. The first two configurations modeled the measured frequency response for the PNL probe design in air. The conclusion from this effort is that the WSU computer calculations were able to reproduce the PNL measurements.

The third configuration calculated the effect on coil response of different conductivities outside the fiberglass LOW. The conclusion reached from this effort was that for the present PNL measurements, and assuming the EMI electronics can distinguish a one-degree phase difference between received signals, the moisture content could be determined to $\pm 4 \mathrm{wt} \%$ free water with the PNL EMI probe design.

The fourth configuration modeled coil effects for different media reluctance outside the fiberglass LOW. The conclusion for this case was that ferromagnetic ions in solution should not interfere with EMI measurements of conductivity.

The fifth configuration modeled different-sized LOWs and simulated LOWs with air gaps. The conclusion for this model was that an air gap outside the LOW would have some effect on the EMI signal, as yet unquantified.

The final configuration modeled a surface moisture measurement in a pancake geometry. The conclusion from this effort is that surface probes can be successfully applied to the tank waste environment, but the surface coil needs more design to optimize the EMI signal for the waste tank moisture ranges. In conclusion, the WSU support for the EMI probe is providing important insight and understanding about operation and calibration of the EMI moisture measuring device.

Initial procurement of EMI hardware and analysis software has been completed. The items will be set up and integrated to begin experimenting with different probe designs and calibration standards. The purchase request for two specialty probes is currently being processed. 
PNL will provide data for berichmark conductivity measurements using their EMI equipment. These data will be used to ensure the finite element analysis has modeled the probe environment correctly and to determine the accuracy of the WSU code.

Small-scale tests using waste simulants at the Westinghouse Hanford Company Chemical Engineering Laboratory are complete. Simulants tested were T-Plant, U-Plant, In-Farm, 101-SY with organic, 101-SY without organic, and a potassium nitrate solution. Preliminary results indicated that electrical conductivity is a function of moisture content as well as temperature. Temperature effects are being evaluated further.

- Planned Work for Subsequent Months. PNL will design a portable calibration standard for the final EMI probe design. PNL will also assist in technology transfer of EMI probe data collection and analysis methods.

EMI probe modeling will continue at WSU with the goals of: (1) developing a benchmark modeling case that agrees with PNL data; (2) determining the depth of penetration into the waste surveilled with different probe designs; and (3) designing portable and laboratory calibration standards.

Recently purchased EMI equipment will be installed in a Westinghouse Hanford Company laboratory in order for Operations personnel to become familiar with data collection and analysis and to develop data collection standards. In addition, the equipment will be used in laboratory testing with several experimental probes to determine a final probe design.

Data collected from small-scale simulant testing at the Westinghouse Hanford Company Chemical Engineering Laboratory will be compiled and analyzed to determine the effect of moisture concentration and temperature on electrical conductivity. These results will be documented in a report.

- Problem Areas and Action Taken. A procurement requisition has been prepared for a dedicated surveillance van that would deploy the EMI probe, as well as the new neutron probes, in the tank farms. Approval of the procurement requisition is on hold. Existing surveillance vans are dedicated to routine neutron and gamma scans and usually are available only on a limited overtime basis. Alternate EMI measurement arrangements at ferrocyanide tanks, including the refurbishment of an old surveillance van, are being considered.

\section{- Milestone Status.}

- May 30, 1995. Westinghouse Hanford Company acquires an EMI system compatible with surveillance van application. If procurement of the surveillance van is not approved, this milestone may need to be redefined. 
- September 30, 1995. Westinghouse Hanford Company issues a report, cleared for public release, describing the FY 1995 engineering testing of the EMI moisture monitoring system. The report will describe the equipment and procedures necessary for deployment of the EMI probe in tanks for routine monitoring of moisture levels in ferrocyanide and organic tanks.

\subsubsection{Moisture Retention Properties of Ferrocyanide Sludge and Saltcake Simulants}

The moisture content of ferrocyanide sludge is very critical in preventing exothermic ferrocyanide/nitrate-nitrite reactions. Studies are underway to evaluate the moisture retention properties of ferrocyanide tank sludge and saltcake simulants as they relate to possible waste tank leaks, tank stabilization by pumping, and possible evaporation from exposed surfaces. Previous work (Epstein et al. 1994) has shown that ferrocyanide sludge cannot dry sufficiently to be chemically reactive during interim storage, either globally or locally. Dryout mechanisms evaluated included global evaporation, removal of liquid by leakage or pumping, boiling as a result of hot spots, and enhanced surface evaporation from hot spots. Current work is focusing on moisture retention in saltcake material, especially after a tank has been interim stabilized.

Sludge Moisture Modeling. Modeling calculations are being performed to estimate the moisture-retaining capability of ferrocyanide waste in typical Hanford Site tank systems. The effort focuses on evaluating the impact of consolidation and surface evaporation processes. Computer models are employed to estimate the moisture retention within the matrix and to determine surface drying of both sludge and saltcake waste. To accomplish these objectives, the hydraulic properties of actual sludges and saltcake porous media must be compared with tested waste simulants, and their physical properties must be correlated.

- Progress During Reporting Period. The objective of this effort is to conduct modeling calculations to predict the moisture-retaining capability of ferrocyanide tank waste sludge and saltcake in a typical tank system.

Modeling Emphasis. Efforts were initiated to examine the moisture-retention behavior of saltcake waste. Generally, saltcake waste is found as a crystal-grained, porous medium overlying a sludge layer. An example of ferrocyanide waste tanks with saltcake is the BY Tank Farm group. Tanks containing mainly sludge are typical of the $\mathrm{C}$ and $\mathrm{T}$ Tank Farms. Previous modeling has emphasized sludge consolidation under self-weight for tanks containing entirely sludge-type waste. Sludge waste was shown to resist drying out by gravity drainage; however, sludge may be vulnerable to drying out at the surface by evaporation. The issue for saltcake is how dry the surface can become after tank stabilization or after saltwell liquid pumping that drains the saltcake portion of the waste. 
Permeability is the property of a porous medium that determines how rapidly liquid will flow through it under an unopposed hydraulic gradient; that is, for a hydraulic system not in a static equilibrium condition. Permeability is essentially a measure of the area available for liquid conduction through a porous medium. Permeability reflects the size of pores contained in a medium, and the pore sizes are related, to some extent, to the size of grains or solid structures forming the medium. Permeability divided by the liquid's viscosity determines the hydraulic conductivity used in Darcy's law to model flow through the medium in the hydraulic pressure gradient field.

Saltcake differs from sludge in that it has a somewhat fixed pore structure when drained or stabilized, whereas sludge does not. The particles or grains in sludge are not necessarily fully forced together, but salt grains are in contact to form a mostly rigid matrix. Sludge particles are mainly insoluble chemicals, with all soluble salts in the surrounding solution. Saltcake, however, is the excess precipitated salt, not being soluble in the available water or salt-saturated liquid. Salt crystals can grow or dissolve over time, thus changing the structure of the medium. At present, it is not known whether the structure of typical saltcake has been adequately characterized to model flow through it. To overcome the lack of information on saltcake waste properties, models that use assumed waste hydraulic properties are presently being employed to test the understanding of saltcake moisture retention behavior. The calculations are being compared with known in-tank observations of waste behavior to confirm or disprove whether the hypothesized descriptions of waste hydraulic properties are correct.

Any theory describing the hydraulic properties of these two distinct tank waste types must take into account the above-mentioned physical characteristics. Modeling moisture flow in such tank waste media must account for how permeability depends on the porous matrix nature. The approach of this modeling task will be to attempt to relate the hydraulic properties of tank waste to the waste's grain size distribution. However, if that approach proves to be unworkable because the structural properties of saltcakes are too diverse or variable, then an indirect approach for inferring hydraulic properties would be appropriate instead. By using an indirect approach, hydraulic properties would be inferred from the tank waste response to pumping.

The liquid permeability, in Darcy units, for saltcake is typically about a thousand or, even ten thousand, times greater than that for sludges (fractions of a millidarcy for sludge simulants). Consequently, interstitial liquid in saturated saltcake can be drained relatively rapidly by pumping from a saltwell, whereas sludge cannot be drained this way. Moreover, saltcake is mainly a rigid medium when drained or dried. Consequently, drained saltcake likely has a fixed bulk volume. Thus, drained saltcake should behave as a rigid porous matrix with a fixed permeability. On the other hand, sludges can be consolidated to reduced bulk volumes by the expulsion of 
interstitial liquid. Therefore, the permeability of sludge will continually vary depending on consolidation conditions. Sludge permeability will decrease as the waste becomes more compressed.

In tanks like 241-BY-104, the overburden of a saltcake layer will also contribute to sludge compression. If a sludge is not already fully consolidated under a particular overburden, the expulsion of liquid from the sludge can force additional liquid up into an overlying saltcake, thus increasing its wetness over time. Therefore, long-term settling of sludge under a saltcake layer could contribute to re-wetting of the saltcake following stabilization pumping. The re-wetting moisture would be manifested as a gradual rise in the interstitial liquid level (ILL), after being drawn down to the capillary holdup height above the sludge layer. Also, following pumping, liquid held in the unsaturated zone above the holdup height (and at distance from the saltwell) would continue to drain downward and accumulate on the sludge layer until a new hydrostatic equilibrium is established. How long this rebound of ILL lasts depends on the liquid retention relationship and conductivity for the unsaturated zone. It is not certain at this time whether this rebound process needs to be modeled, except for the further decrease of moisture it produces in the compressed sludge layer below a saltcake overburden.

In a saltcake waste with a given porosity, the volumetric liquid content is less than its maximum saturation value for any height above the $I L L$, provided that the ILL falls below the saltcake surface. In a drained saltcake porous medium, the liquid content is maintained by capillary rise above the ILL. A part of the IIL height, which is in the liquid saturated zone, is held up by capillary pressure. If a salt layer were drained to the maximum amount possible from a penetrating saltwell, an IIL height, called the capillary fringe or holdup height, would remain held by capillary rise. Also, the capillary holdup is the height of the IIL in the cake above the standing liquid level in a saltwell. The volumetric liquid content distribution in the profile of a saltcake is a direct reflection of the capillary liquid retention relation for the particular porous medium. Thus, to estimate the moisture content distribution in a drained and stabilized saltcake waste (i.e., all remaining liquid is retained by capillarity against gravity), the retention relation must be known or measured.

Given the volumetric liquid distribution in a saltcake profile, the weight percentage of water in the bulk medium can be immediately estimated by presuming the interstitial liquid is saturated with dissolved saltcake. In this case the weight percent water is given by

$$
\mathrm{Wt} \% \text { Water }=\mathrm{P}_{\mathrm{w}} \bullet(\text { liquid density/bulk density) } \bullet \text { (liquid content) }
$$

where $P_{w}$ is the percent water in the salt-saturated liquid. The bulk density of saltcake in this formula is dependent on the porosity, or void fraction (called "void"), and the present volumetric liquid content. The bulk density equals 
(grain density) $\bullet(1$-void $)+($ liquid density $) \bullet$ (liquid content).

For tank 241-BY-104 the void was reported to be as great as 0.46 , by Grigsby et al. (1992). Grain density and liquid density were reported to be $2.09 \mathrm{~g} / \mathrm{cc}$ and $1.45 \mathrm{~g} / \mathrm{cc}$, respectively. Because the maximum liquid content, as a fraction, is equal to void, the bulk density would be about $1.8 \mathrm{~g} / \mathrm{cc}$ for saturated saltcake. However, Grigsby et al. (1992) reported $1.61 \mathrm{~g} / \mathrm{cc}$, which possibly indicates that the salt sample was drained somewhat before being measured. Percent water content of supernatant, $\mathbf{P}_{w}$, was found to be $48 \%$ for tank 241-BY-104. These values yield about $20 \mathrm{wt} \%$ water for saltcake. If the higher, saturated bulk density were used, then the value would be about $18 \mathrm{wt} \%$. Thus, it is typical for weight percent water of saltcake to be about $20 \mathrm{wt} \%$, when saturated. But in the unsaturated zone above the $I L L$, the value would be reduced by the fraction of liquid content that remained held up by capillarity following stabilization. For instance, if liquid content was 50\% of void, then the weight percent water drops to about $11 \%$.

Therefore, compared to sludges, which typically have no less than $40 \mathrm{wt} \%$ water even when consolidated, the weight percent water of drained saltcake is likely to be substantially less than $20 \mathrm{wt} \%$. This occurs even though the amount of void space in the saltcake still retains a substantial quantity of liquid.

An important consideration for saltcake is the holdup height. If this value were large, say 90 to $120 \mathrm{~cm}$, for a similar thickness of saltcake layer, then the layer would remain nearly saturated even when stabilized. On the other hand, a very thick saltcake layer could be very dry near the surface on a weight percent basis. In contrast, the holdup height for very large salt grains would be relatively small. Hence, it is important to be able to estimate the holdup height in order to evaluate moisture retention under equilibrium stabilized conditions.

Modeling Activities. Because it is very difficult and expensive to obtain tank salt samples and make direct capillary liquid retention measurements, past studies on saltcake properties are being examined for relevant information. A critical review of several documents was completed to examine the veracity of reported saltcake data. An informal analysis of holdup height based on reports by Handy (1975), Kirk (1980), Metz (1976), Strachan (1975), and Atherton (1974) was recently transmitted to Westinghouse Hanford Company and PNL Waste Tank Safety managers. The similarity of past studies was discussed in the analysis, as briefly reviewed below.

A formula given by Atherton (1974) and then reproduced and employed by Grigsby . et al. (1992, equation 4-5, page 4-93) is a valuable, simple means for estimating capillary holdup height from porosity, liquid surface tension, liquid density, and typical grain size diameter for the porous medium. But it remains to be demonstrated that the formula is applicable to saltcake as a type of porous medium. The formula stems from some early experimental work done by Dombrowski and Brownell (1954). These authors developed a correlation between holdup height (also called drain height) 
and the measured permeability for various particle sizes and shapes of certain granular porous media. Fluids of different density and surface tension are also used to fully develop the correlation for a range of liquid properties. Unfortunately, these authors leave the impression that there is always a certain level of residual liquid, only about 7.5 volume percent (vol\%), held just above the holdup height. But this is a special consequence of the homogeneous (narrow) size distribution of particle packs used in their experiments. A wider range in the particle size distribution will generally produce a more gradual reduction of liquid content above the holdup height.

It was determined that although Handy's (1975) and Strachan's (1975) estimates of saltcake permeability, 22 darcy and 2 darcy, respectively, seemed reasonable, their measured holdup heights seemed to underestimate the possible capillary rise that is consistent with grain size based on Atherton's formula. Strachan was the only one to attempt a full measurement of the liquid retention relationship. However, that measurement appeared flawed for various reasons. Those experimental issues were discussed in the informal analysis.

Examination of a report on tank 241-BY-104 auger samples, taken near the saltcake waste surface by Beck et al. (1992), indicated high capillary retention of 17 to $20 \mathrm{wt} \%$ water, 90 to $120 \mathrm{~cm}$ above the presumed IIL. This result seems consistent with the Atherton formula's estimate of holdup for a grain size range reported by Strachan for a simulant cake. Unfortunately, the crystal size distribution was destroyed by the present method of digesting tank 241-BY-104 salt samples in pure water before measuring particle sizes. Future particle size distribution measurements of tank waste should try to obtain the crystal grain sizes, as well as insoluble particle sizes.

Atherton's formula could also be used to reconcile the result that capillary holdup in sludge would not be great, unless the porosity was quite low (around 30 to 50 vol\%), as associated with highly compressed sludge. For sludge with 85 to 95 vol\% porosity (typical of the In-Farm and U-Plant simulants and the sludge samples of Risenmay [1985]), the capillary rise for small particle sizes (5 to 10 micrometers) would be only a fraction of a meter, instead of several meters high ( 6 down to 3 meters, respectively). This result further confirms that liquid is held strongly in sludges by forces other than capillarity, when not substantially compressed to 30 vol\% porosity instead of about 90 vol\%. It further supports the concept that electrolytic forces or ionic separation forces hold the liquid and fine particles together in sludge. Considerable stress must be applied to sludge material to force particles closer together and thereby expel excess liquid when the volume is compressed. Thus, sludge drains by settlement under the stress of self-weight or overburden, whereas liquid in saltcake drains out under the gravitational gradient associated with the liquid's density, provided that the containing tank allows leakage at the bottom or is pumped. 
A computer program was created to estimate the retention relation from the grain size distribution of a granular medium. The implemented model is based on soil physics work by Arya and Paris (1981). This model constructs the pore size distribution determining the capillary pressure from the particle grain sizes. Using the method of Tyler and Wheatcraft (1989), an undetermined fitting parameter in this retention model can be evaluated from the fractal dimension of the particle size distribution when the distribution is consistent with the simple theory. This parameter would be calibrated to actual measurements of liquid retention for a sample. Beginning with this retention model and a measurement of saturated conductivity, the conductivity as a function of decreasing volumetric liquid content can be estimated. A computer code based on the paper of Mishra et al. (1989) that further examines the uncertainty of parameters in the Arya-Paris model was obtained and is operational. The code, called SOILPROP ${ }^{6}$, is in FORTRAN object form only and cannot be modified for possibly different salt liquid properties because it is a proprietary code. This Arya-Paris model, however, is a considerable simplification for the complexity of a saltcake crystal matrix, and it is by no means certain at this time how well it can predict the actual hydraulic properties of saltcake. The model's validity remains to be tested in the future on saltcake simulants and actual tank core samples. It must be demonstrated that saltcake viewed as a rigid porous matrix is indeed consistent with the capillary model's assumptions before being applied to estimate moisture retention.

- Planned Work for Subsequent Months. Modeling of the moisture retention and drainage of sludge and saltcake waste will continue. Experiments are planned that will measure sludge consolidation and water loss from saltcake as a function of water evaporation by exposure of simulant materials to varying relative humidities in an enclosed chamber or by gravity draining. The quantitative information from these experiments will be used to develop models for evaluating moisture retention in tank waste.

- Problem Areas and Actions Taken. None.

- Milestone Status.

- September 29, 1995. PNL issues a report, cleared for public release, on FY 1995 work on waste moisture modeling activities.

- September 30, 1995. Westinghouse Hanford Company issues a publicly available report evaluating water loss from sludge and saltcake as a function of relative humidity and gravity draining.

${ }^{6}$ SOILPROP is a proprietary program to estimate unsaturated soil hydraulic properties from particle size distribution data. User and Technical Guide, Version 2.1, Environmental Systems \& Technologies, Inc., 2608 Sheffield Drive, Blacksburg, VA, 24060-8270. 


\subsection{CHEMICAL REACTION STUDIES}

"The schedule for the program on study of the chemical properties and explosive behavior of the waste in these tanks is indefinite and does not reflect the urgent need for a comprehensive and definitive assessment of the probability of a violent chemical reaction. The study should be extended to other metallic compounds of ferrocyanide that are known or believed to be present in the tanks, so that conclusions can be generalized as to the range of temperature and other properties needed for a rapid chemical reaction with sodium nitrate."

Chemical reaction studies on ferrocyanide waste simulants are being conducted by Westinghouse Hanford Company, FAI; PNL, and Los Alamos National Laboratory (LANL). Westinghouse Hanford Company and PNL have produced flowsheet simulant materials for testing and characterization. FAI is conducting adiabatic calorimetry and propagation tests on these same flowsheet materials and on stoichiometric mixtures of pure sodium nickel ferrocyanide and sodium nitrate/nitrite. The test program at LANL was completed in FY 1993.

\subsubsection{Chemical Reaction Studies at Pacific Northwest Laboratory}

Chemical reaction studies are continuing at PNL using flowsheet simulant materials. Waste studies addressing DNFSB Recommendation 90-7.5 are being conducted to determine: (1) the aging effects (hydrolysis and radiolysis) from more than 35 years of storage in the tanks; (2) the speciation of cyanides found in the actual tank waste; and (3) modeling calculations to predict the moisture-retaining capability of ferrocyanide waste in a typical tank system (this work is reported in Section 3.4.3).

\section{- Progress During Reporting Period.}

Aging Studies. Hydrolysis experiments conducted at $100{ }^{\circ} \mathrm{C}$ were completed this quarter. Samples of In-Farm-1B ferrocyanide flowsheet simulant material in $2 M$ $\mathrm{NaOH}$ at $100^{\circ} \mathrm{C}$ were irradiated at $1 \times 10^{5} \mathrm{Rad}$ per hour $(\mathrm{Rad} / \mathrm{h})$ for about three weeks. The ammonia concentrations in solution in vessels removed from the gamma pit at various times over the course of the experiment are shown in Figure 3-5. Data from previous experiments conducted at $90^{\circ} \mathrm{C}$ are shown for comparison. At $100^{\circ} \mathrm{C}$ the hydrolysis of ferrocyanide (normally soluble in $2 M \mathrm{NaOH}$ ) is complete after 12 days based on the number of moles of ammonia detected in solution (105\% accounted for). The ion selective electrode used for ammonia determination is accurate to within 3\% at these concentrations. After 19 days, more ammonia was produced (119\% of the expected amount) possibly indicating that some of the ferrocyanide normally insoluble in the $2 \mathrm{M} \mathrm{NaOH}$ was destroyed. Over $50 \%$ of the soluble ferrocyanide (cyanide) in the non-irradiated control was hydrolyzed to ammonia after 19 days at $100{ }^{\circ} \mathrm{C}$. 
The change in soluble iron concentration for gamma-irradiated solutions (line connecting data points) and non-irradiated controls (points) is shown in Figure 3-6. The decrease in iron concentration in the gamma irradiated solutions can be described as pseudo-first order with a rate constant of 0.25 day $^{-1}$.

In previous experiments at $90^{\circ} \mathrm{C}$, with varying initial ferrocyanide concentrations, this rate constant was determined to be 0.12 day $^{-1}$. The soluble iron concentrations in the $100{ }^{\circ} \mathrm{C}$ control experiments were very near the expected starting concentrations. For example, the total soluble iron concentration in the 19-day control did not decrease appreciably even though over $50 \%$ hydrolysis had occurred. In contrast, after 50\% hydrolysis in the gamma-irradiated solutions, the total soluble iron concentration had decreased by about $70 \%$. The reason for the different behavior between the irradiated solutions and the non-irradiated controls is not known. However, one difference is that while both experiments are initially under an argon atmosphere, the gamma-irradiated experiments are in an environment in which oxidants, such as hydroxyl radicals and oxygen gas, are produced by the radiation. The oxidants may produce Fe(III) compounds, which typically have solubilities lower than their $\mathrm{Fe}(\mathrm{II})$ analogs. Infrared spectroscopy and other methods will be used to gain information about iron speciation.

During hydrolysis, the concentration of soluble nickel has been observed to increase. Nickel originally precipitates as nickel hydroxide when the In-Farm flowsheet material dissolves in caustic. The redissolution is thought to occur when a portion of the cyanide ion, liberated from iron during hydrolysis, reacts with nickel hydroxide to form soluble nickel cyanide.

To investigate the hydrolysis behavior of nickel cyanide, a hydrolysis experiment was conducted in which $0.0128 \mathrm{MK}_{2} \mathrm{Ni}(\mathrm{CN})_{4}$ was heated to $90^{\circ} \mathrm{C}$ in $2 \mathrm{M} \mathrm{NaOH}$ and irradiated at an incident dose rate of $1.07 \times 10^{5} \mathrm{Rad} / \mathrm{h}$ for about three weeks. The concentration of ammonia generated with time is shown in Figure 3-7.

Concentrations at 2, 5, and 7 days are low because experiments were run in thick vessels. Gamma radiation promotes hydrolysis, as seen previously; however, the precipitate from the reaction is not nickel hydroxide, but appears to be metallic nickel. Reduction of metal ions by gamma irradiation is known to give metal powders. Analyses to test for metallic nickel and to determine the concentrations of other reaction products are being performed. 
Figure 3-5. Ammonia Production During In-Farm-1B Hydrolysis at 90 and $100{ }^{\circ} \mathrm{C}$. Data From Irradiated (Lines) and Non-Irradiated (Points) Experiments are Shown.

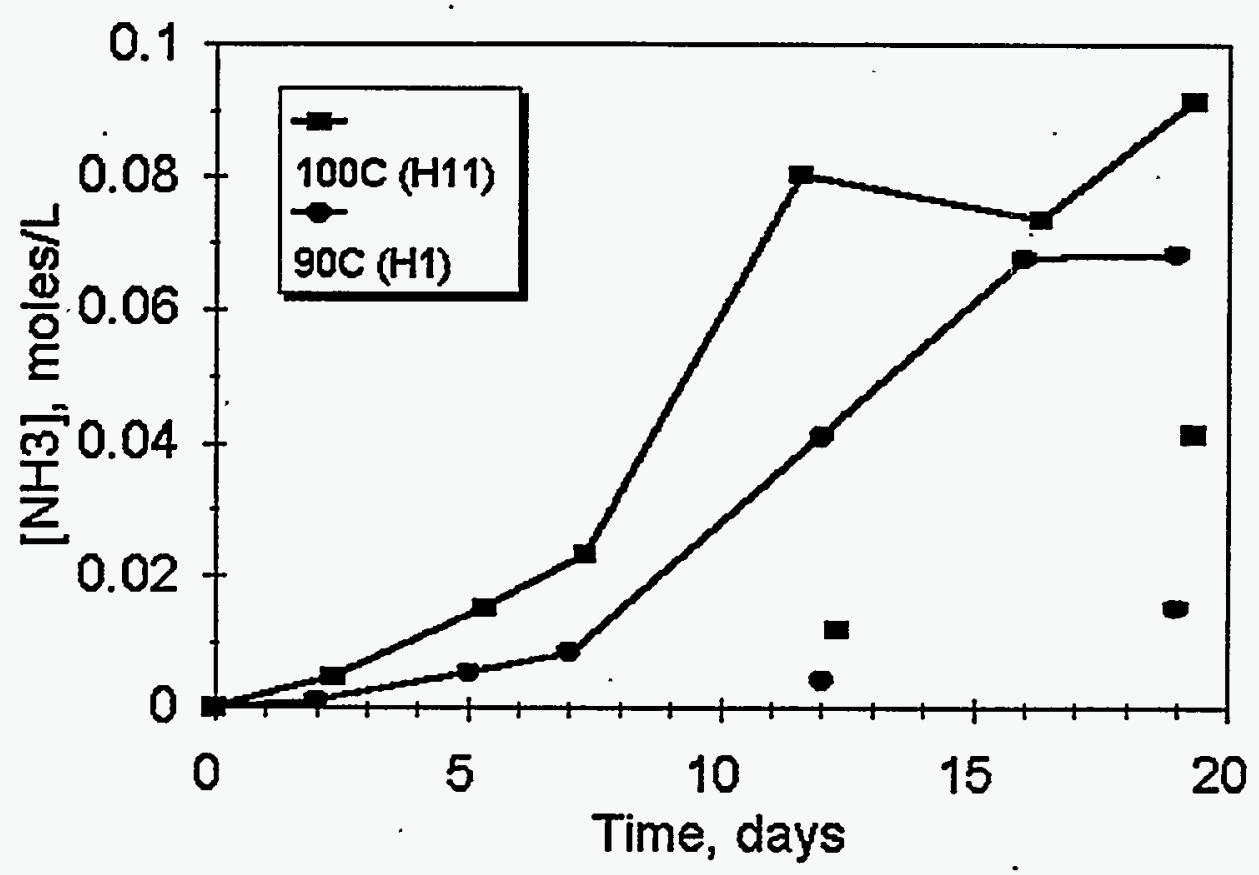

Long-term hydrolysis experiments at $\mathrm{pH} 10$ and $60^{\circ} \mathrm{C}$ were initiated during the quarter. These conditions, which simulate conditions present in some ferrocyanide tanks, are less favorable to ferrocyanide degradation via hydrolysis than higher $\mathrm{pH}$ and higher temperature experiments. Four identical vessels containing solutions of InFarm-1B are being irradiated and will be removed individually at about six-week intervals over the nearly eight-month experiment.

Cesium Uptake Capacity. During the quarter, approximately $800 \mathrm{~g}$ of U-Plant-2 ferrocyanide waste simulant and $900 \mathrm{~g}$ of In-Farm-2 simulant were prepared and homogenized in preparation for distribution experiments and column testing. The U-Plant-2 simulant was analyzed for total ferrocyanide by FTIR spectroscopy and found to contain 1.3E-4 moles $\mathrm{Na}_{2} \mathrm{NiFe}(\mathrm{CN})_{6}$ per gram of sample. The isolated simulants had an average solids content of 37 percent. Radiological column experiments examining the intercalation and layering characteristics of the U-Plant-2 and In-Farm-2 ferrocyanide waste simulant were planned. 
Figure 3-6. Change in Total [Fe] During the Hydrolysis of In-Farm-1B at $100{ }^{\circ} \mathrm{C}$. Data From Gamma-Irradiated (Line Connected Points) and Non-Irradiated (Points) Experiments are Shown.

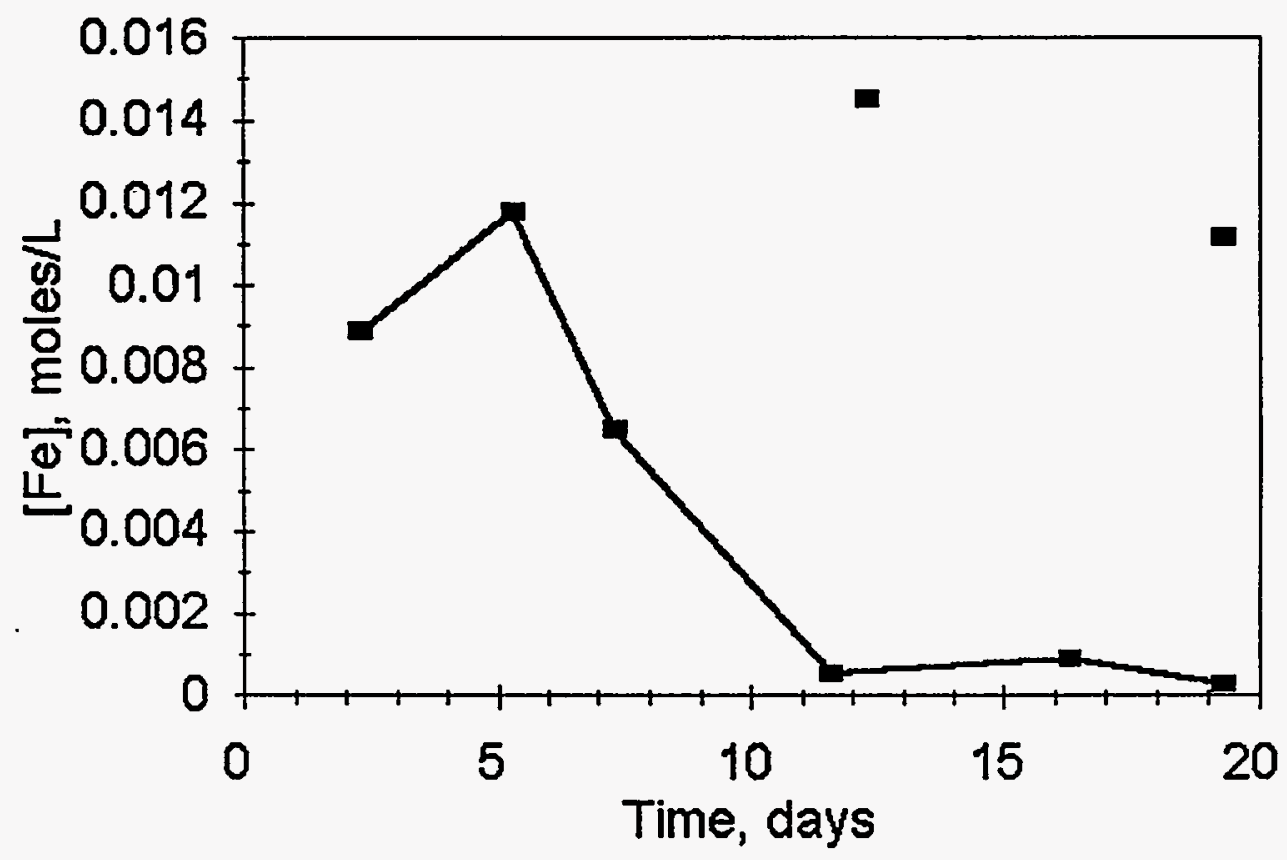

Distribution measurements $\left(\mathrm{K}_{\mathrm{d}}\right)$ were performed for cesium ion exchange using centrifuged U-Plant-2 simulant waste solids as the ion exchange material. The experimental conditions and results are shown in Table 3-3. The concentration of sodium was kept constant as the concentration of cesium was varied. This test allows for the measurement of $\mathrm{K}_{\mathrm{d}}$ values at various cesium levels under conditions that bound the conditions possible in ferrocyanide waste under U-Plant flowsheet conditions. The cesium-to-nickel ferrocyanide ratio was varied from lower than expected in UPlant waste $(0.0010)$ to much greater than expected (200 times). This allows for: (1) examination of how U-Plant-2 solids behave under a wide range of conditions representing possible localized conditions within the tanks; and (2) determination of what would happen at the surface of a layer of U-Plant-2 solids in continual contact with solutions of cesium-containing waste. 
Figure 3-7. Ammonia Production During the Hydrolysis of $\mathrm{K}_{2} \mathrm{Ni}(\mathrm{CN})_{4}$ at $90^{\circ} \mathrm{C}$.

Data From Gamma-Irradiated (1.07 x $10^{5} \mathrm{Rad} / \mathrm{h}$ Incident Dose Rate) and Non-Irradiated Experiments are Shown.

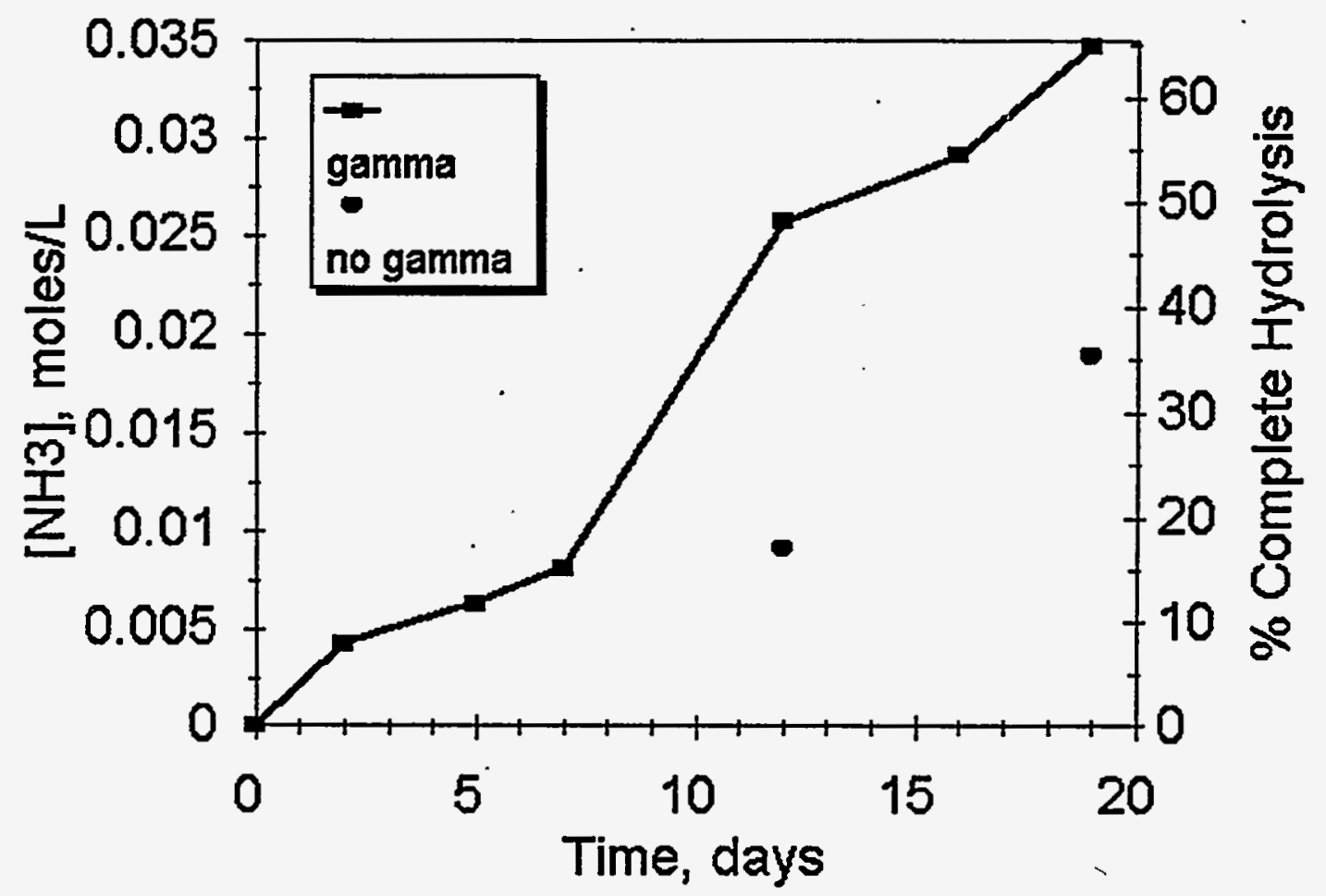

The results in Table 3-3 confirm the results of the initial cold experiments. As expected, as the ratio of cesium to nickel ferrocyanide increases, the percent of cesium removed from solution decreases. In the initial scavenging campaign, the mole ratio of cesium to nickel ferrocyanide was approximately 0.006 to 0.003 . Under these conditions and at lower ratios, cesium is readily removed from solution. At higher ratios, the effectiveness of the nickel ferrocyanide as a cesium ion exchanger decreases significantly. Under the conditions of this experiment (varying the sodium-to-cesium concentration) the maximum capacity of the nickel ferrocyanide appears to be approximately 0.35 moles of cesium per mole of nickel ferrocyanide.

The intercalation experiments for In-Farm-2 and U-Plant-2 were initiated in February 1995 , when radioactive operations in the 325 Building laboratories were approved. Six columns of each simulant were prepared and are currently settling until no discernable change in the solid level is observed. When no further visible settling of the solids is observed, cesium and ${ }^{137} \mathrm{Cs}$-spiked supernate will be added to the columns to examine the intercalation of the cesium. 
Table 3-3. Effect of Cesium Concentration on the Cesium Distribution Coefficients for U-Plant-2 Simulant at $\mathrm{pH} 9$.

\begin{tabular}{|c|c|c|c|c|c|}
\hline $\begin{array}{c}\text { Sample } \\
\text { No. }\end{array}$ & $\begin{array}{c}\mathrm{Na} / \mathrm{Cs} \\
\text { Ratio }\end{array}$ & $\begin{array}{c}\mathrm{Cs} / \mathrm{NiFeCN} \\
\text { Ratio }\end{array}$ & $\begin{array}{c}{[\mathrm{Cs}]} \\
\text { moles }\end{array}$ & $\begin{array}{c}\mathrm{Kd} \\
\mathrm{mL} / \mathrm{g}\end{array}$ & $\begin{array}{c}\% \mathrm{Cs} \\
\text { Removed }\end{array}$ \\
\hline 1 & $4.50 \mathrm{e}+02$ & 206 & $1.30 \mathrm{e}-02$ & 0.45 & $1 \%$ \\
2 & $9.00 \mathrm{e}+02$ & 100 & $6.47 \mathrm{e}-03$ & 1.7 & $4 \%$ \\
3 & $1.80 \mathrm{e}+03$ & 51 & $3.22 \mathrm{e}-03$ & 1.3 & $3 \%$ \\
4 & $3.60 \mathrm{e}+03$ & 25 & $1.61 \mathrm{e}-03$ & 2.5 & $6 \%$ \\
5 & $9.00 \mathrm{e}+03$ & 10 & $6.50 \mathrm{e}-04$ & 2.1 & $5 \%$ \\
6 & $1.80 \mathrm{e}+04$ & 5 & $3.24 \mathrm{e}-04$ & 3.0 & $7 \%$ \\
7 & $4.50 \mathrm{e}+04$ & 2 & $1.29 \mathrm{e}-04$ & 4.6 & $10 \%$ \\
8 & $8.70 \mathrm{e}+04$ & 1 & $6.69 \mathrm{e}-05$ & 9.3 & $19 \%$ \\
9 & $1.80 \mathrm{e}+05$ & 0.50 & $3.29 \mathrm{e}-05$ & 17 & $30 \%$ \\
10 & $8.90 \mathrm{e}+05$ & 0.10 & $6.57 \mathrm{e}-06$ & 180 & $82 \%$ \\
11 & $1.70 \mathrm{e}+06$ & 0.050 & $3.35 \mathrm{e}-06$ & 620 & $94 \%$ \\
12 & $8.70 \mathrm{e}+06$ & 0.010 & $6.66 \mathrm{e}-07$ & 6600 & $99 \%$ \\
13 & $1.80 \mathrm{e}+07$ & 0.005 & $3.30 \mathrm{e}-07$ & 6400 & $99 \%$ \\
14 & $3.40 \mathrm{e}+07$ & 0.0027 & $1.70 \mathrm{e}-07$ & 6500 & $99 \%$ \\
15 & $8.90 \mathrm{e}+07$ & 0.0010 & $6.56 \mathrm{e}-08$ & 6500 & $99 \%$ \\
\hline
\end{tabular}

- Planned Work For Subsequent Months. Aging experiments will continue using the In-Farm flowsheet simulant. A knowledge of factors that impact the free cyanide concentration in solution is important to understanding the mechanism(s) involved in the hydrolysis reactions. Experiments are being conducted to determine factors that may have influenced hydrolysis rates under actual tank waste conditions. The aging tests will be completed this fiscal year. 
Cyanide speciation studies, using ion chromatography methods and solution IR methods, will continue until the validated techniques and procedures can be routinely applied to samples in analytical laboratories at PNL and Westinghouse Hanford Company. Current efforts are directed toward evaluating the techniques on core samples from tanks 241-C-109 and 241-C-112.

- Problem Areas and Actions Taken. All laboratory work was halted within radioactive control areas in the 325 Building in April 1994. Restart plans for the building were approved by DOE in December 1994, and resumption of work on an individual task and laboratory basis started this quarter. The cyanide speciation and cesium uptake tasks resumed in late January 1995.

\section{- Milestone Status.}

- July 31, 1995. PNL issues a report, cleared for public release, on solution IR and ion chromatography cyanoferrate speciation activities and application for routine measurements in the analytical laboratories. This milestone date was set this quarter to be completed six months after restart of this radiological activity in the 325 Building.

- July 31, 1995. PNL issues a report, cleared for public release, on cesium uptake capacity of ferrocyanide. This milestone date was set this quarter to be completed six months after restart of this radiological activity in the 325 Building.

- September 29, 1995. PNL issues the final report integrating all Ferrocyanide Safety Program hydrolysis and radiolysis aging activities.

\subsubsection{Preparation and Characterization of Ferrocyanide Simulants}

Pure sodium nickel ferrocyanide is being prepared and analyzed to determine its chemical reaction properties with stoichiometric mixtures of sodium nitrate/nitrite as a function of water content. These tests are being conducted by FAI to clearly define the margin of safety between the theoretical and experimental propagation limits for ferrocyanide. These tests are run in the FAI reactive systems screening tool. These tests and previous tests with simulants--along with analyses of actual tank waste samples, waste tank monitoring, and waste modeling--provide information to characterize with a great deal of assurance safety concerns relating to the sludge in the ferrocyanide tanks.

- Progress During Reporting Period. Chemical analyses of the vacuum-dried $\left(60{ }^{\circ} \mathrm{C}\right.$ for 24 hours) test batch of single-phase disodium mononickel ferrocyanide $\left(\mathrm{Na}_{2} \mathrm{NiFe}(\mathrm{CN})_{6}\right)$ was completed this quarter. Analyses included inductively coupled plasma, X-ray fluorescence, ion chromatography, atomic adsorption, total cyanide, FTIR, and simultaneous thermogravimetric, differential scanning calorimetry and mass spectrographic analysis of the offgases. These analyses support the conclusion 
that this test material is single-phase $\mathrm{Na}_{2} \mathrm{NiFe}(\mathrm{CN})_{6}$. A large batch (about 300 grams) of this material is being prepared at Westinghouse Hanford Company to provide material for propagation tests at FAI.

Results from the analyses are summarized in Table 3-4. All cations not listed were below detection limits (except calcium was analyzed at $0.01 \mathrm{wt} \%$ ). The calculated formula for the single-phase ferrocyanide sample, based on these analyses, is $\mathrm{Na}_{2} \mathrm{NiFe}(\mathrm{CN})_{5.80} \cdot 5.91 \mathrm{H}_{2} \mathrm{O}$ plus $0.37 \mathrm{NaNO}_{3}$. X-ray diffraction results reported earlier also supported the conclusion that this material contains a single-phase ferrocyanide.

Table 3-4. Analyses of Single-Phase $\mathrm{Na}_{2} \mathrm{NiFe}(\mathrm{CN})_{6}$

Test Material.

\begin{tabular}{|c|r|r|}
\hline Analyte & $\begin{array}{c}\text { Average Concentration } \\
\text { (wt\%) }\end{array}$ & $\begin{array}{c}\text { Ratio to Iron } \\
\text { (mole/mole) }\end{array}$ \\
\hline $\mathrm{Fe}$ & 12.2 & 1.00 \\
\hline $\mathrm{Ni}$ & 12.4 & 0.97 \\
\hline $\mathrm{Na}$ & 12.0 & 2.39 \\
\hline $\mathrm{CN}^{-}$ & 32.9 & 5.80 \\
\hline $\mathrm{NO}_{3}^{-}$ & 5.1 & 0.37 \\
\hline $\mathrm{H}_{2} \mathrm{O}$ & 23.2 & 5.91 \\
\hline
\end{tabular}

The contact temperature ignition (CTI) criterion developed by FAI was updated this quarter and provided to Westinghouse Hanford Company for final review (Fauske 1995). Application of the CTI condition to ferrocyanide leads to a lower bound theoretical fuel concentration value with zero free water of $10 \mathrm{wt} \%$ $\mathrm{Na}_{2} \mathrm{NiFe}(\mathrm{CN})_{6}$ that would ensure no condensed-phase propagating reactions could occur. This compares to the $8 \mathrm{wt} \%$ value that supported closure of the Ferrocyanide USQ (Postma et al. 1994a). After a review of this document is complete, it will be cleared for public release.

- Planned Work for Subsequent Months. About $300 \mathrm{~g}$ of single-phase $\mathrm{Na}_{2} \mathrm{NiFe}(\mathrm{CN})_{6}$ will be prepared and shipped to FAI. FAI will conduct propagation geometry tests using stoichiometric mixtures of sodium nickel ferrocyanide and sodium nitrate/nitrite with varying amounts of water. The tests will determine the effects of upward propagation, larger-diameter samples $(50 \mathrm{~mm})$, and the sample temperature, on the temperature required for propagation. 
The theoretical derivation of the CTI criterion presented in Fauske (1995) is being peer reviewed and will be provided next quarter as a Westinghouse Hanford Company report available to the public.

Additional tests with organic surrogates and ferrocyanide simulants will also be conducted. This work is expected to result in one set of criteria that can be applied to both organic and ferrocyanide tanks to define the upper composition fuel limit for safe storage of the waste in the tanks.

- Milestone Status.

- July 31, 1995. Westinghouse Hanford Company releases a report, approved for public release, documenting the development and confirmation by testing of the CTI criterion model.

- September 30, 1995. Westinghouse Hanford Company completes the ferrocyanide calorimetry and propagation test program at FAI as specified by Westinghouse Hanford Company, and prepares reports, available for public release, that support final resolution of the Ferrocyanide Safety Issue.

\subsection{EMERGENCY RESPONSE PLANNING}

"The Board had recommended 'that an action plan be developed for the measures to be taken to neutralize the conditions that may be signaled by alarms.' Two types of measures are implied: actions to respond to unexpected degradation of a tank or its contents, and actions to be taken if an explosion were to occur. Your implementation plan stated that 'the current contingency plans ... will be reviewed and revised if needed.' We do not consider that this proposed implementation of the Board's recommendation is adequately responsive. It is recommended that a written action plan founded on demonstrated principles be prepared as soon as possible, that would respond to indications of onset of abnormal temperatures or other unusual conditions in a ferrocyanide-bearing tank, to counter any perceived growth in hazard. A separate emergency plan should be formulated and instituted, covering measures that would be taken in event of an explosion or other event leading to an airborne release of radioactive material from the tanks, and that would protect personnel both on and off the Hanford Site. The Board believes that even though it is considered that the probability is small that such an event will occur, prudence dictates that steps be taken at this time to prepare the means to mitigate the unacceptable results that could ensue."

The original Action Plan for Response to Abnormal Conditions in Hanford Radioactive Waste Tanks Containing Ferrocyanide (Cash and Thurman 1991) was prepared in response to DNFSB Recommendation 90-7.6. The plan describes the steps to be taken if a temperature increase trend above the tank temperature baseline is measured in any of the ferrocyanide tanks. The document was revised to include the monitoring criteria and responses for 
abnormal levels of flammable and toxic gases, as well as the reporting requirements, if established criteria are exceeded. The second revision of the plan was released in June 1994 (Fowler 1994).

The Tank Farm Stabilization Plan For Emergency Response (WHC 1991) was issued in March 1991. If a radioactive release from a ferrocyanide tank were to occur, it would be detected by one or more radiation monitoring systems. Significant airborne or ground surface releases that spread beyond the immediate tank or tank farm would be detected by the tank farm area radiation detectors. These monitoring systems are on all tank farms. An emergency involving an underground radioactive waste storage tank is a unique event with potentially serious consequences both onsite and offsite. The Stabilization Plan provides quick, preplanned actions that can be used to stabilize an emergency event at an underground radioactive waste storage tank.

All actions with respect to emergency planning, emergency event recognition, protective action recommendations, and emergency response procedures have been completed. Further revisions and occasional validation exercises will be accomplished as part of the normal Westinghouse Hanford Company and DOE emergency planning efforts. No further reporting on these issues is planned, and this part of DNFSB Recommendation 90-7.6 is considered complete and closed.

DOE considers this recommendation to be closed with the provisos that the abnormal conditions response plan and emergency plans are reviewed on a periodic basis and revised and updated as required to incorporate any additional controls determined appropriate by the ongoing Waste Tank Safety Program investigations (e.g., the Action Plan for Response to Abnormal Conditions in Hanford Site Radioactive Waste Tanks Containing Ferrocyanide was updated and released in June 1994 [Fowler 1994]); and that validation exercises for various waste tank accident scenarios are conducted periodically (exercises for the tank farms are conducted every two years).

- Progress During Reporting Period. As noted in previous reports, all of the planned milestones for this task were completed.

- Planned Work For Subsequent Months. None planned.

- Problem Areas and Action Taken. None.

- Milestone Status. All milestones have been completed. 


\subsection{IMPLEMENTATION OF THE WYDEN AMENDMENT}

The Wyden Amendment (Public Law 101-510, Section 3137, 1990) requires that:

"...the Secretary of Energy shall identify which single-shelled or double-shelled high-level nuclear waste tanks at the Hanford Nuclear Reservation, Richland, Washington, may have a serious potential for release of high-level waste due to uncontrolled increases of temperature or pressure. After completing such identification, the Secretary shall determine whether continuous monitoring is being carried out to detect a release or excessive temperature or pressure at each tank so identified. If such monitoring is not being carried out, as soon as practicable the Secretary shall install such monitoring, but only if a type of monitoring that does not itself increase the danger of a release can be installed."

\subsection{THE WATCH LIST}

In March 1989, using process knowledge, process records, transfer records, and log books, Westinghouse Hanford Company (Nguyen 1989) identified 22 Hanford Site tanks as potentially containing $1,000 \mathrm{~g}$-moles $(211 \mathrm{~kg}$ [465 lb]) or more of ferrocyanide [as the $\mathrm{Fe}(\mathrm{CN})_{6}^{4}$ anion]. To avert possible injury to personnel and damage to the facility or environment, strict controls were identified for these and other Safety Issue tanks. These controls were described in the document, Operating Specifications for. Watch List Tanks (WHC 1990). Tanks identified via this document (see WHC [1994] for latest revision) have been commonly referred to as Watch List tanks. Two additional ferrocyanide tanks were identified in January 1991 (Borsheim and Cash 1991), increasing the number of ferrocyanide tanks to 24 .

In November 1990, the Wyden Amendment (Public Law 101-510, Section 3137, 1990) was enacted. This law required the identification of Hanford Site tanks that may have a serious potential for release of high-level waste. In February 1991 (Harmon 1991), the 24 ferrocyanide tanks were among the tanks identified, and were included in the subsequent July 1991 report to Congress (Watkins 1991) that responded to the Wyden Amendment. However, re-examination of the historical records (Borsheim and Simpson 1991) indicated that six of the 24 tanks did not contain the requisite $1,000 \mathrm{~g}$-moles of ferrocyanide. Therefore, these six tanks should not have been included on the Watch List nor been identified in the response to the Wyden Amendment. The six tanks were subsequently removed from the Watch List (Anttonen 1993, Sheridan 1994b) (Note: these tanks do not contain greater than $8 \mathrm{wt} \% \mathrm{Na}_{2} \mathrm{NiFe}(\mathrm{CN})_{6}$ and should not be on the Watch List for this reason also).

As part of the overall safety screening module being conducted by Westinghouse Hanford Company Tank Waste Remediation System, all of the Hanford Site SSTs will be core sampled and characterized (Note: the $115 \mathrm{cal} / \mathrm{g}$ of dry fuel criterion established for 
ferrocyanide tanks is now the adopted limit used for safety screening [Babad and Redus 1994]). Eighteen ferrocyanide tanks are currently on the Watch List, and no more tanks are expected to be added to the Ferrocyanide Watch List.

Work conducted since 1991 on ferrocyanide reactions has resulted in a change of the criterion used for placing ferrocyanide tanks on the Watch List. The 1,000 g-mole inventory criterion has now been replaced with a fuel concentration criterion of $115 \mathrm{cal} / \mathrm{g}$ of dry sample (this is an energy equivalent to a concentration of $8 \mathrm{wt} \% \mathrm{Na}_{2} \mathrm{NiFe}(\mathrm{CN})_{6}$ in the waste). This fuel concentration criterion more accurately reflects the risk associated with ferrocyanide tanks. Ferrocyanide tanks with concentrations less than an energy equivalent of $8 \mathrm{wt} \%$ $\mathrm{Na}_{2} \mathrm{NiFe}(\mathrm{CN})_{6}$ cannot support a propagating reaction, and are categorized as safe. Detailed rationale for the $115 \mathrm{cal} / \mathrm{g}$ of dry fuel concentration criterion is presented in Postma et al. (1994a).

Core sampling and characterization efforts will determine the ferrocyanide concentration for those tanks that bound aging (see Sections 2.2 and 3.4). After adequate characterization, if these tanks contain concentrations less than $8 \mathrm{wt} \% \mathrm{Na}_{2} \mathrm{NiFe}(\mathrm{CN})_{6}$ (i.e., the fuel value of the maximum concentration is less than $115 \mathrm{cal} / \mathrm{g}$ ), then a request will be made by Westinghouse Hanford Company for DOE concurrence to remove all of the ferrocyanide tanks from the Watch List.

Some sample bias and analytical error is unavoidable; therefore, confidence intervals have been established to specify when it is appropriate to conclude that a ferrocyanide tank contains concentrations less than an energy equivalent of $8 \mathrm{wt} \% \mathrm{Na}_{2} \mathrm{NiFe}(\mathrm{CN})_{6}$. An $80 \%$ confidence interval was chosen for tanks with a fuel concentration of $8 \mathrm{wt} \%$ $\mathrm{Na}_{2} \mathrm{NiFe}(\mathrm{CN})_{6}$. That is, if five ferrocyanide tanks contain exactly an energy equivalent of 8 wt\% $\mathrm{Na}_{2} \mathrm{NiFe}(\mathrm{CN})_{6}$, statistically, four tanks would remain on the Watch List and one tank would be removed. The possibility of removing a ferrocyanide tank from the Watch List decreases substantially as the fuel concentration increases. The confidence intervals increase to $95 \%$ and $99 \%$ at $\mathrm{Na}_{2} \mathrm{NiFe}(\mathrm{CN})_{6}$ concentrations of $12 \%$ and $15 \mathrm{wt} \%$, respectively. Detailed discussions on how sample bias and analytical error are factored into determining the actual fuel concentrations in a ferrocyanide tank are given in the Ferrocyanide Data Quality Objectives document (Meacham et al. 1994a).

- Planned Work To Complete Program. An increased understanding of ferrocyanide aging indicates that little ferrocyanide remains, and the assumption that it is necessary to core sample all ferrocyanide tanks may not be valid. By characterizing the waste in only those tanks that bound aging (i.e., tanks with conditions least conducive to aging), the Ferrocyanide Safety Issue could be resolved much earlier and at a substantially reduced cost. As more core sample data become available, the need to sample all the ferrocyanide tanks will be reexamined. 
- Milestones.

- January 31, 1996. Westinghouse Hanford Company issues documentation supporting resolution of the Ferrocyanide Safety Issue for the four C Farm tanks, and recommends resolution of the Ferrocyanide Safety Issue for C Farm tanks.

- July 31, 1996. Westinghouse Hanford Company receives DOE approval to resolve the Ferrocyanide Safety Issue for C Farm tanks.

- March 31, 1997. Westinghouse Hanford Company prepares documentation to support resolution of the Ferrocyanide Safety Issue for the remaining 14 tanks, and recommends Ferrocyanide Safety Issue resolution for all remaining tanks.

- September 30, 1997. Westinghouse Hanford Company receives DOE approval to resolve the Ferrocyanide Safety Issue. This completes the Ferrocyanide Safety Program.

\subsection{TEMPERATURE MONITORING}

The installation of temperature monitoring capabilities is discussed in Sections 3.1.2.1 and 3.2.2. Installation of instrument trees and continuous temperature monitoring are considered prudent waste management practices (monitoring temperatures helps follow the initiators' side of the fire triangle). Therefore, new instrument trees will be installed in ferrocyanide tanks, even though the ferrocyanide waste has aged and little fuel value remains.

- Planned Work To Complete Program. Instrument trees will be inserted in the remaining ferrocyanide tanks (currently there are five ferrocyanide tanks that still require installation of trees). This will provide two operating instrument trees in all but three ferrocyanide tanks (see Section 3.1.2.1 for discussion on instrument trees). All instrument trees will be connected to TMACS for continuous monitoring. Completion of this task is anticipated by the end of FY 1995.

\section{- Milestones}

- September 30, 1995. Westinghouse Hanford Company completes installation of instrument trees in all ferrocyanide tanks and connects trees to TMACS. Existing temperature-sensing elements in tanks 241-BY-105 and -106 will be replaced, if necessary. This milestone completes Tri-Party Agreement Milestone M-40-02. 


\subsection{PRESSURE MONITORING}

The ferrocyanide tanks were initially identified as having "a serious potential for release" and were placed on the Watch List because insufficient data were available on the probability for ferrocyanide-nitrate/nitrite reactions. Pressure monitoring is not presently installed on the ferrocyanide tanks. It would take several years to install pressure monitoring instrumentation because of the capital project time cycle. Ferrocyanide waste has probably degraded (aged) significantly, and all of the tanks may now contain less than the $8 \mathrm{wt} \% \mathrm{Na}_{2} \mathrm{NiFe}(\mathrm{CN})_{6}$ fuel concentration specified for the safe category (see also Postma et al. 1994a). This eliminates the need for continuous pressure monitoring for offgases from a ferrocyanide reaction.

The rationale for not installing pressure monitors in ferrocyanide tanks was prepared and submitted to DOE in July 1994 (Payne 1994b). Low gas generation rates (Fowler and Graves 1994) and the low potential for exothermic ferrocyanide reactions (Postma et al. 1994a) indicated that continuous pressure monitoring is not warranted.

- Planned Work For Subsequent Months. No additional work is planned in this area since DOE has concurred that pressure monitoring is not required as stated in the revised Ferrocyanide Safety Issue Program Plan (O'Leary 1994).

- Milestones. None. 


\subsection{PROGRAM SCHEDULES AND MILESTONES}

Schedules (Figure 5-1) are presented in this section. The schedules review milestones for FY 1994 through the expected end of the program in FY 1997. The sequence and anticipated completion dates of the major milestones leading to resolution of the Ferrocyanide Safety Issue are presented. Closure of DNFSB recommendations are indicated on the schedule as diamonds, and completion of interim milestones are indicated as triangles. The schedules are statused through March 31, 1995. 
Figure 5-1. Ferrocyanide Waste Tank Safety Schedule. (Sheet 1 of 2)

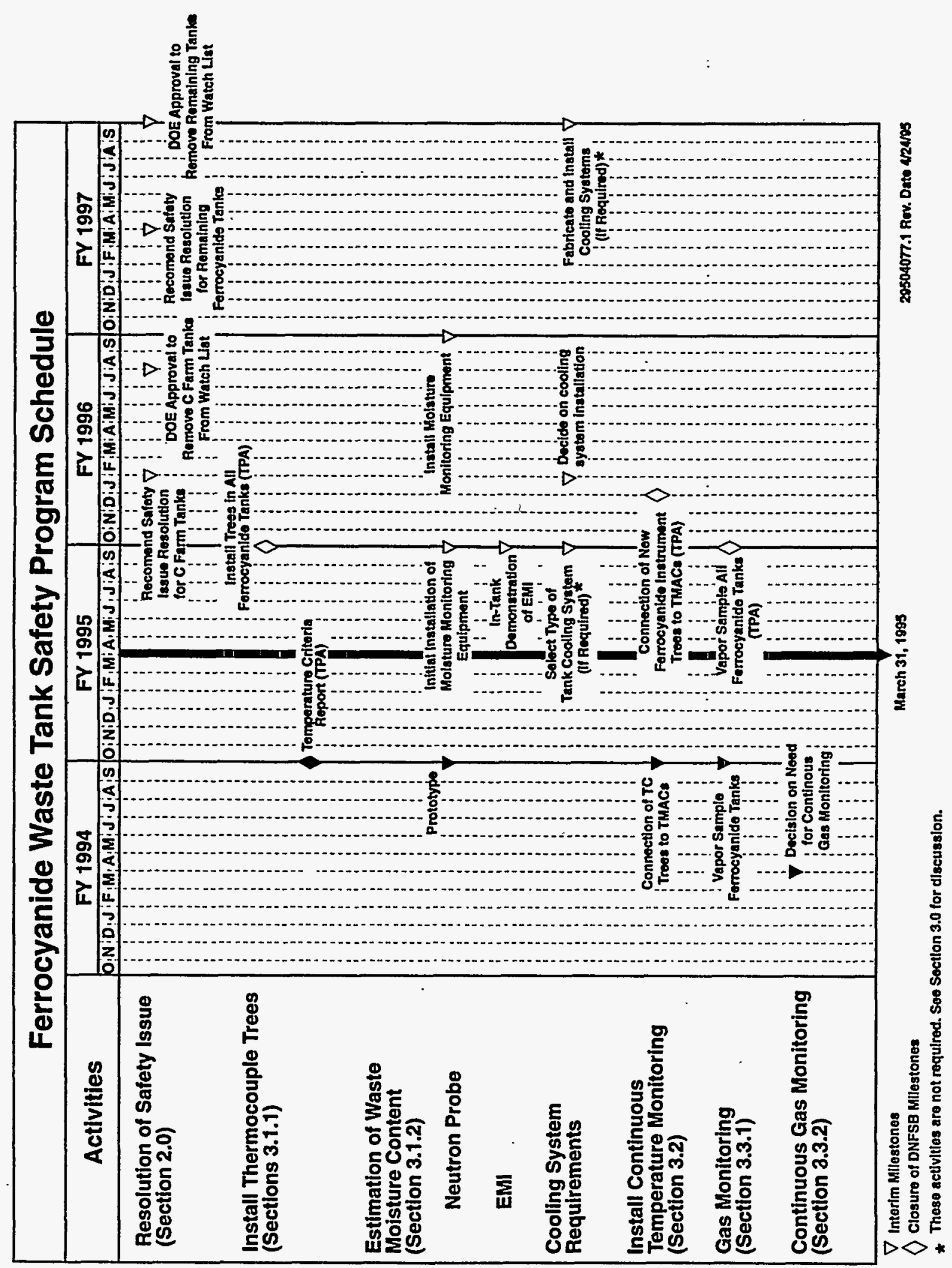




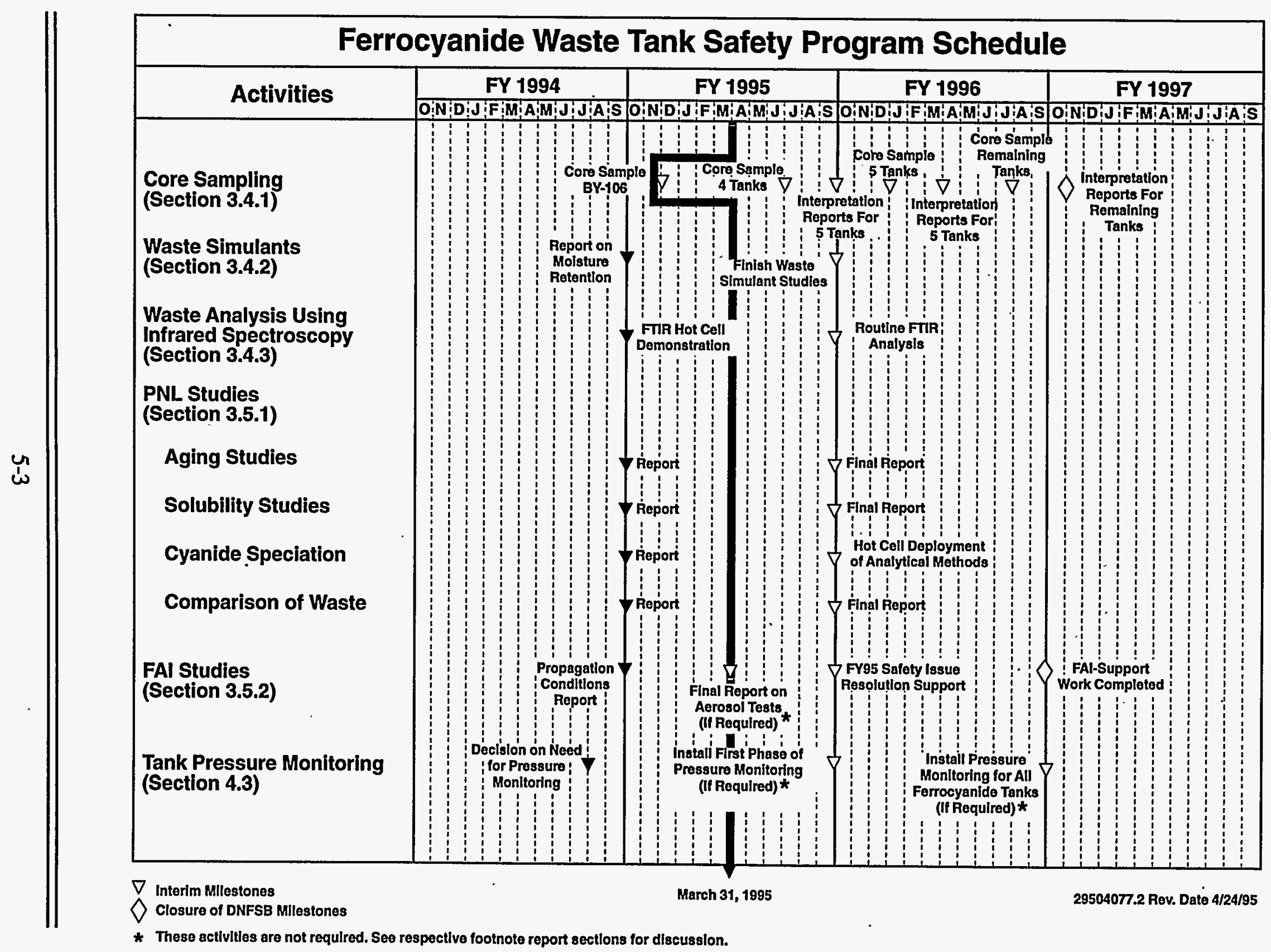


This page intentionally left blank. 


\subsection{REFERENCES}

Alumkal, W. T., 1993, Ferrocyanide Safety Program: Request for Removal of Two Tanks from the Safety Watch List, (letter 9304645B.R2 to J. H. Anttonen, DOE-RL, September 20), Westinghouse Hanford Company, Richland, Washington.

Anttonen, J. H., 1993, Resolution of Unreviewed Safety Question (USQ) for Four Ferrocyanide Tanks, (letter 9304645B/93-CAB-223 to T. M. Anderson, President, Westinghouse Hanford Company, July 9), U.S. Department of Energy, Richland Operations Office, Richland, Washington.

Arya, L. M., and J. F. Paris, 1981, "A Physicoempirical Model to Predict the Soil Moisture Characteristic from Particle-Size Distribution and Bulk Density," Soil Science Society of America Jour., 45:1023-1030.

Atherton, J. A., 1974, Prediction of Liquor Retention in Salt Cake and Sludges, ARH-CD-230, Atlantic Richfield Hanford Company, Richland, Washington.

Babad, H., and K. S. Redus, 1994, Tank Safety Screening Data Quality Objective, WHC-SD-WM-SP-004, Rev. 0, Westinghouse Hanford Company, Richland, Washington.

Beck, M. A., D. B. Bechtold, and B. E. Hey, 1992, Analysis Report for 241-BY-104 Auger Samples, WHC-SD-WM-TI-540, Westinghouse Hanford Company, Richland, Washington.

Borsheim, G. L., and R. J. Cash, 1991, Unusual Occurrence - Addition of Two Tanks to List of Unreviewed Safety Question Tanks Containing Ferrocyanide, WHC-91-0096-TFARM, Final, dated February 13, Westinghouse Hanford Company, Richland, Washington.

Borsheim, G. L., and B. C. Simpson, 1991, An Assessment of the Inventories of Ferrocyanide Watch List Tanks, WHC-SD-WM-EP-133, Rev. 0, Westinghouse Hanford Company, Richland, Washington.

Borsheim, G. L., J. E. Meacham, R. J. Cash, and B. C. Simpson, 1993, Ferrocyanide Safety Program: Rationale for Removing Six Tanks From the Safety Watch List, WHC-MR-0429, Westinghouse Hanford Company, Richland, Washington.

Bussell, J. H., 1992, Engineering Evaluation of Thermocouples in Ferrocyanide Watch List Tanks, WHC-SD-WM-ER-134, Rev. 0 and Rev. 0A, Westinghouse Hanford Company, Richland, Washington. 
Cady, H. H., 1993, Evaluation of Ferrocyanide/Nitrate Explosive Hazard, LA-12589-MS, Los Alamos National Laboratory, Los Alamos, New Mexico.

Cash, R. J., 1991, Implementation Plan for the Defense Nuclear Facilities Safety Board Recommendation 90-7, WHC-EP-0415, Rev. 0, Westinghouse Hanford Company, Richland, Washington.

Cash, R. J., and J. Thurman, 1991, Action Plan for Response to Abnormal Conditions in Hanford Site Radioactive Waste Tanks Containing Ferrocyanide, EP-0407, Rev. 0, Westinghouse Hanford Company, Richland, Washington.

Claybrook, S. W., and S. A. Wood, 1994, Organic Evaporation in Waste Tank C-103, WHC-SD-WM-ER-344, Rev. 0, Westinghouse Hanford Company, Richland, Washington.

Crowe, R. D., M. Kummerer, and A. K. Postma, 1993, Estimation of Heat Load in Waste Tanks Using Average Vapor Space Temperatures, WHC-EP-0709, Westinghouse Hanford Company, Richland, Washington.

Deaton, D. E., 1990, Unusual Occurrence - Unreviewed Safety Questions Regarding Tanks Containing Ferrocyanide, WHC-90-B003-R1 (Update 10-22-90), Westinghouse Hanford Company, Richland, Washington.

Dickinson, D. R., J. M. McLaren, G. L. Borsheim, and M. D. Crippen, 1993, Ferrocyanide Safety Program: Credibility of Drying Out Ferrocyanide Tank Waste by Hot Spots, WHC-EP-0648, Rev. 0, Westinghouse Hanford Company, Richland, Washington.

DOE, 1987, Final Environmental Impact Statement, Disposal of Hanford Defense High-Level, Transuranic and Tank Waste, Hanford Site, Richland, Washington, DOE/EIS-0113, Vol. 1 through 5, U.S. Department of Energy, Washington, D.C.

DOE, 1994a, Recommendation 93-5 Implementation Plan, DOE/RL 94-0001, U.S. Department of Energy, Richland Operations Office, Richland, Washington.

DOE, 1994b, Program Plan for Resolution of the Ferrocyanide Waste Tank Safety Issue at the Hanford Site, DOE/RL-94-110, Rev. 1, U.S. Department of Energy, Richland Operations Office, Richland, Washington.

Dombrowski, H. S., and L. E. Brownell, 1954, "Residual Equilibrium Saturation of Porous Media," Industrial and Engineering Chemistry, 46(6):1207-1219. 
Epstein, M., H. K. Fauske, M. D. Crippen, D. R. Dickinson, J. D. McCormack, R. J. Cash, J. E. Meacham, and C. S. Simmons, 1994, Ferrocyanide Safety Program: An Assessment of the Possibility of Ferrocyanide Sludge Dryout, WHC-EP-0816, Westinghouse Hanford Company, Richland, Washington.

Fauske, H. K., 1995, The Contact-Temperature Ignition (CTI) Criterion for Propagating Chemical Reactions and Application to Hanford Waste, FAI/94-103, Fauske and Associates, Inc., Burr ·Ridge, Illinois.

Fischer, G., and M. Bader, 1994, "Melt Film Technique for IR Spectroscopy," American Laboratory, pp. 32c-32h, November 1994.

FR, 1990, "Implementation Plan for Recommendation 90-3 at the Department of Energy's Hanford Site, Washington," Federal Register, Defense Nuclear Facilities Safety Board Recommendation 90-7, Vol. 55, No. 202, pp. 42243 - 42244.

Fowler, K. D., 1994, Action Plan for Response to Abnormal Conditions in Hanford Site Radioactive Waste Tanks Containing Ferrocyanide, WHC-EP-0407, Rev. 2, Westinghouse Hanford Company, Richland, Washington.

Fowler, K. D., and R. D. Graves, 1994, Decision Analysis for Continuous Cover Gas Monitoring of Ferrocyanide Watch List Tanks, WHC-EP-0743, Westinghouse Hanford Company, Richland, Washington.

Gerton, R. E., 1994, Environmental Assessment (EA) and Finding of No Significant Impact (FONSI) for the Waste Tank Safety Program at the Hanford Site, (DOE/EA-0915), (letter 9402034B/94-SST-053 to President, Westinghouse Hanford Company, March 8), U.S. Department of Energy, Richland, Washington.

Grigsby, J. M., D. B. Bechtold, G. L. Borsheim, M. D. Crippen, D. R. Dickinson, G. L. Fox, D. W. Jeppson, M. Kummerer, J. M. McLaren, J. D. McCormack, A. Padilla, B. C. Simpson, and D. D. Stepnewski, 1992, Ferrocyanide Waste Tank Hazard Assessment--Interim Report, WHC-SD-WM-RPT-032, Rev. 1, Westinghouse Hanford Company, Richland, Washington.

Handy, L. L., 1975, Flow Properties of Salt Cake for Interstitial Removal/Immobilization Development Program, ARH-C-6, Atlantic Richfield Hanford Company, Richland, Washington.

Harmon, H. D., 1991, Safety Measures for Waste Tanks at Hanford Site; Richland, Washington, (letter 9059124.1 to R. E. Gerton, DOE-RL, February 8), Westinghouse Hanford Company, Richland, Washington. 
Hertelendy, N. A., 1993, Final Test Report - Ultra High Pressure Water as a Tool to Bore, Drill, Cut or Penetrate Hard Saltcake-Like Nuclear Waste, WHC-SD-WM-RPT-132, Rev. 0, Westinghouse Hanford Company, Richland, Washington.

King, C. V., 1994, Ferrocyanide Safety Program: Results of Relative Humidity Experiments Using Ferrocyanide Waste Simulants, WHC-SD-WM-TRP-215, Rev. 0, Westinghouse Hanford Company, Richland, Washington.

Kirk, J. J., 1980, Permeability, Porosity and Capillarity of Hanford Waste Material and Its Limits of Pumpability, RHO-CD-925, Rockwell Hanford Company, Richland, Washington.

Kress, T., K. Bandyopadhyay, P. d'Entremont, S. Slezak, and M. Reich, 1990, Risk of a Ferrocyanide Explosion in the Hanford Waste Tank Farm, (memorandum to John Tseng, DOE-HQ, September 20), Ad Hoc Task Force formed by U.S. Department of Energy to evaluate the ferrocyanide safety concerns at the Hanford Site, Oak Ridge National Laboratory, Oak Ridge, Tennessee.

McLaren, J. M., 1993, Ferrocyanide Safety Program: Updated Thermal Analysis Model for Ferrocyanide Tanks with Application to Tank 241-BY-104, WHC-EP-0669, Westinghouse Hanford Company, Richland Washington.

McLaren, J. M., 1994a, Ferrocyanide Safety Program: Thermal Analysis of Ferrocyanide Tanks, Group 1, WHC-EP-0729, Westinghouse Hanford Company, Richland, Washington.

McLaren, J. M. 1994b, Ferrocyanide Safety Program: Thermal Analysis of Ferrocyanide Watch List Tanks, Group II, WHC-EP-0794, Westinghouse Hanford Company, Richland, Washington.

Meacham, J. E., H. Babad, and H. Toffer, 1993, Moisture Monitoring of Ferrocyanide Tanks: An Evaluation of Methods and Tools, WHC-EP-0658, Westinghouse Hanford Company, Richland, Washington.

Meacham, J. E., R. J. Cash, G. T. Dukelow, J. W. Buck, C. M. Anderson, B. A. Pulsipher, J. J. Toth, and P. J. Turner, 1994a, Data Requirements for the Ferrocyanide Safety Issue Developed Through the Data Quality Objectives Process, WHC-SD-WM-DQO-007, Rev. 0, Westinghouse Hanford Company, Richland, Washington.

Meacham, J. E., R. J. Cash, and G. T. Dukelow, 1994b, Quarterly Report on the Ferrocyanide Safety Program for the Period Ending June 30, 1994, WHC-EP-0474-13, Westinghouse Hanford Company, Richland, Washington. 
Metz, W. P., 1976, A Topical Report on Interstitial Liquid Removal from Hanford Salt Cakes, ARH-CD-545, Atlantic Richfield Hanford Company, Richland, Washington.

Mishra, S., J. C. Parker, and N. Singhal, 1989, "Estimation of Soil Hydraulic Properties and Their .Uncertainty from Particle Size Distribution Data," Jour. of Hydrology, 108:1-18.

NIOSH, 1995, NIOSH Pocket Guide to Chemical Hazards, U. S. Department of Health and Human Resources, National Institute for Occupational Safety and Health, Cincinatti, Ohio.

Nguyen, D. M., 1989, Data Analysis of Conditions in Single-Shell Tanks Suspected of Containing Ferrocyanide, (internal memo 13314-89-025 to N. W. Kirch, March 2), Westinghouse Hanford Company, Richland, Washington.

O'Leary, H. R., 1994, [Transmittal of "Program Plan for Evaluation of the Ferrocyanide Waste Tank Safety issue at the Hanford Site, "DOE/RL-94-110], (letter to J. T. Conway, Chairman, Defense Nuclear Facilities Safety Board, December 2), U.S. Department of Energy, Washington, D.C.

Payne, M. A., 1994a, Ferrocyanide Safety Program: Transmittal of General Accounting Office Closeout Report, (letter 9454280 to R. E. Gerton, DOE-RL, June 16), Westinghouse Hanford Company, Richland, Washington.

Payne, M. A., 1994b, Ferrocyanide Safety Program: Continuous Pressure Monitoring in Ferrocyanide Watch List Tanks, (letter 9455175 to R. E. Gerton, DOE-RL, July 29), Westinghouse Hanford Company, Richland, Washington.

Peach, J. D., 1990, Consequences of Explosion of Hanford's Single-Shell Tanks are Understated, (letter B-241479 to M. Synar, Chairman, Environment, Energy, and Natural Resources Subcommittee, Committee on Government Operations, House of Representatives, October 10), GAO/RCED-91-34, U.S. General Accounting Office, Washington, D.C.

Postma, A. K., J. E. Meacham, G. S. Barney, G. L. Borsheim, R. J. Cash, M. D. Crippen, D. R. Dickinson, J. M. Grigsby, D. W. Jeppson, M. Kummerer, J. M. McLaren, C. S. Simmons, and B. C. Simpson, 1994a, Ferrocyanide Safety Program: Safety Criteria for Ferrocyanide Watch List Tanks, WHC-EP-0691, Westinghouse Hanford Company, Richland, Washington. 
Postma, A. K., D. B. Bechtold, G. L. Borsheim, J. M. Grigsby, R. L. Guthrie, M. Kummerer, M. G. Plys, and D. A. Turner, 1994b, Safety Analysis of Exothermic Reaction Hazards Associated with the Organic Liquid Layer in Tank 241-C-103, WHC-SD-WM-SARR-001, Rev. 0, Westinghouse Hanford Company, Richland, Washington.

Public Law 101-510, Section 3137, 1990, Safety Measures for Waste Tanks at Hanford Nuclear Reservation, U.S. Congress, Washington, D.C. [Also referred to as the Wyden Amendment]

Rebagay, T. V., R. J. Cash, and J. E. Meacham, 1994, Evaluation of FTIR Based Analytical Methods for the Analysis of Simulated Wastes, WHC-SD-WM-TI-664, Rev. 0, Westinghouse Hanford Company, Richland, Washington.

Reffner, J. A., W. T. Wihlborg, and S. W. Strand, 1991, "Chemical Microscopy of Surfaces by Grazing Angle and Internal Reflection FTIR Microscopy," American Laboratory, April 1991.

Reich, F. R., R. E. Johnson, B. L. Philipp, J. B. Duncan, and G. L. Schutzenhofer, 1995, Summary of Fiscal Year 1994 Near-Infrared Spectroscopy Moisture Sensing Activities, WHC-EP-0839, Westinghouse Hanford Company, Richland, Washington.

Relyea, J. F., 1994, The Drying of Sodium Nickel Ferrocyanide at Constant Relative Humidity, (internal memorandum 8H110-JFR-94-054 to D. W. Jeppson, September 23), Westinghouse Hanford Company, Richland, Washington.

Risenmay, H. R., 1985, Consolidation Tests of Synthetic Waste Sludges, (internal memo 65455-85-088 to D. F. Flyckt, August 7), Rockwell Hanford Company, Richland, Washington.

Sheridan, T. R., 1994a, Closure of the Ferrocyanide Unreviewed Safety Question, (letter 9401180/94-SST-052 to A. L. Trego, President, Westinghouse Hanford Company, March 4), U.S. Department of Energy, Richland Operations Office, Richland, Washington.

Sheridan, T. R., 1994b, Approval to Remove Two Ferrocyanide Tanks, 241-BX-102 and 241-BX-106, from the Watch List, (letter 9406684/94-SST-205 to A. L. Trego, President, Westinghouse Hanford Company, November 17), U.S. Department of Energy, Richland Operations Office, Richland, Washington.

Simpson, B. C., G. L. Borsheim, and L. Jensen, 1993a, Tank Characterization Report: Tank 241-C-109, WHC-EP-0688, Westinghouse Hanford Company, Richland, Washington. 
Simpson, B. C., G. L. Borsheim, and L. Jensen, 1993b, Tank Characterization Data Report: Tank 241-C-112, WHC-EP-0640, Rev. 1, Westinghouse Hanford Company, Richland, Washington.

Sloat, R. J., 1954, TBP Plant Nickel Ferrocyanide Scavenging Flowsheet, HW-30399, General Electric Company, Richland, Washington.

Sloat, R. J. 1955, In-Farm Scavenging Operating Procedure and Control Data, HW-38955, General electric Company, Richland, Washington.

Smith, D. A., 1986, Single-Shell Tank Isolation Safety Analysis Report, SD-WM-SAR-006, Rev. 2, Westinghouse Hanford Company, Richland, Washington.

Strachan, D. M., 1975, Permeability, Capillarity, and Pore Volume of Synthetic Hanford Salt Cake, ARH-ST-129, Atlantic Richfield Hanford Company, Richland, Washington.

Toth, J. J., P. G. Heasler, J. G. Hill, M. E. Lerchen, and P. D. Whitney, 1995, Analysis of Organic Carbon and Moisture in Hanford Single-Shell Tank Waste, PNL-10360, Pacific Northwest Laboratory, Richland, Washington.

Tyler, S. W., and S. W. Wheatcraft, 1989, "Application of Fractal Mathematics to Soil Water Retention Estimation;" Soil Science Society of America Jour., 53:987-996.

Wagoner, J. D., 1993, Approval of Hanford Site Tank Farm Facilities Interim Safety Basis, (letter 93-TOB-209 to T. M. Anderson, President, Westinghouse Hanford Company, November 18), U.S. Department of Energy, Richland Operations Office, Richland, Washington.

Watkins, J. D., 1991, Report to United States Congress on Waste Tank Safety Issues at the Hanford Site, (letter to D. Quayle, President of the Senate, July 16), U.S. Department of Energy, Washington, D.C.

Watson, W. T., 1993, Proof of Principle Report for In-Tank Moisture Monitoring Using an Active Neutron Probe, WHC-EP-0695, Westinghouse Hanford Company, Richland, Washington.

Watson, W. T., S. A. Finfrock, and H. Toffer, 1994, Potential Tank Waste Material Anomalies Located Near the Liquid Observation Well: Model Predicted Responses of a Neutron Moisture Detection System, WHC-EP-0809, Westinghouse Hanford Company, Richland, Washington.

WHC, 1990, Operating Specifications for Watch List Tanks, OSD-T-151-00030, Rev. 0, Westinghouse Hanford Company, Richland, Washington. 
WHC, 1991, Tank Farm Stabilization Plan for Emergency Response, WHC-SD-PRP-TI-001, Rev. 0, Westinghouse Hanford Company, Richland, Washington.

WHC, 1994, Operating Specifications for Watch List Tanks, OSD-T-151-00030, Rev. B-2, Westinghouse Hanford Company, Richland, Washington.

WHC, 1995a, 45 Day Safety Screen Results for Tank 241-C-108, Augers 94-012, 94-014, and 94-015, WHC-SD-WM-DP-082, Rev. 0, Westinghouse Hanford Company, Richland, Washington.

WHC, 1995b, 45 Day Safety Screen Results for Tank 241-TY-104 Auger Samples 95-AUG-008 and 95-AUG-009, WHC-SD-WM-DP-101, Rev. 0, Westinghouse Hanford Company, Richland, Washington.

Wood, S. A., 1992, Gas Space Analysis For Tank C-109, WHC-SD-WM-ER-183, Rev. 0, Westinghouse Hanford Company, Richland, Washington. 
APPENDIX A

FERROCYANIDE TANK INFORMATION SUMMARY 
WHC-EP-0474-16

This page intentionally left blank. 
Table A-1. Summary of Contents and Status of Ferrocyanide Tanks."

\begin{tabular}{|c|c|c|c|c|c|}
\hline Tank & $\begin{array}{c}\text { Total waste } \\
\text { volume } \\
(1,000 \mathrm{~L})\end{array}$ & $\begin{array}{c}\mathrm{FeCN}^{\mathrm{b}} \\
(1,000 \mathrm{~g} \text {-mole })\end{array}$ & $\begin{array}{l}\text { Heat load } \\
\qquad(k W)^{c}\end{array}$ & $\begin{array}{l}\text { Maximum } \\
\text { temp. } \\
\left({ }^{\circ} \mathrm{C}\right)\left({ }^{\circ} \mathrm{F}\right)\end{array}$ & Status of tanks \\
\hline BY-103 & 1510 & 66 & 1.6 & $27 \quad 81$ & NS; AL \\
\hline BY-104 & 1540 & 83 & 2.6 & $\begin{array}{ll}52 & 126 \\
45^{\mathrm{e}} & .112\end{array}$ & IS; Sound \\
\hline BY-105 & 1900 & 36 & 2.6 & $\begin{array}{ll}44 & 112 \\
48 & 119\end{array}$ & NS; AL \\
\hline BY-106 & 2430 & 70 & 3.0 & $\begin{array}{ll}53 & 127\end{array}$ & $\mathrm{NS} ; \mathrm{AL}$ \\
\hline BY-107 & 1010 & 42 & 2.6 & $\begin{array}{cc}36 & 97 \\
- \text { ff }^{3} & -\end{array}$ & IS; AL \\
\hline BY-108 & 863 & 58 & 2.7 & $43 \quad 109$ & IS; AL \\
\hline BY-110 & 1510 & 71 & 2.0 & $\begin{array}{ll}48 & 118 \\
42^{e} & 107\end{array}$ & IS; Sound \\
\hline BY-111 & 1690 & 6 & 1.6 & $29^{\circ} \quad 84$ & IS; Sound \\
\hline BY-112 & 1100 & 2 & 1.8 & $32^{\circ} \quad 90$ & IS; Sound \\
\hline C-108 & 250 & 25 & 1.8 & $\begin{array}{ll}22 & 71 \\
23^{\mathrm{e}} & 73\end{array}$ & IS; Sound \\
\hline C-109 & 250 & $6.8^{g}$ & 2.1 & $\begin{array}{ll}24 & 76 \\
25^{e} & 76\end{array}$ & IS; Sound \\
\hline C-111 & 216 & 33 & 2.0 & $22 \quad 71$ & IS; AL \\
\hline C-112 & 394 & $11.5^{\mathrm{g}}$ & 2.2 & $\begin{array}{ll}27 & 80 \\
27^{\circ} & 80\end{array}$ & IS; Sound \\
\hline T-107 & 681 & 5 & 0.9 & $\begin{array}{cc}18 & 65 \\
--f^{f} & -\end{array}$ & NS; AL \\
\hline TX-118 & 1310 & $<3$ & 1.4 & $\begin{array}{cc}25 & 77 \\
--{ }^{f} & --\end{array}$ & IS; Sound \\
\hline TY-101 & 447 & 23 & 0.9 & $20 \quad 65$ & IS; AL \\
\hline TY-103 & 613 & 28 & 1.2 & $20 \quad 69$ & IS; AL \\
\hline TY-104 & 174 & 12 & 0.9 & $\begin{array}{cc}18 & 64 \\
--f^{f} & --\end{array}$ & IS; AL \\
\hline
\end{tabular}


Table A-1 Notes:

- Reflects removal of four ferrocyanide tanks from Watch List in July 1993 and two additional tanks in October 1994. Tank information and temperature data as of March 1995.

b Inventories from Borsheim and Simpson (1991).

c Heat load values from Table 7-1 in Crowe et al. (1993).

d IS - Interim Stabilized Tank; NS - Not Stabilized; AL - Assumed Leaker Tank; Sound - Non-Leaking Tank.

- Readings from new instrument trees; tank 241-BY-105 already had two trees.

f Readings have not yet been taken on this new instrument tree.

g Calculated as ferrocyanide $\left[\mathrm{Fe}\left(\mathrm{CN}_{6}^{4}\right]\right.$ based on the total cyanide values reported in Simpson et al. (1993a, 1993b). 


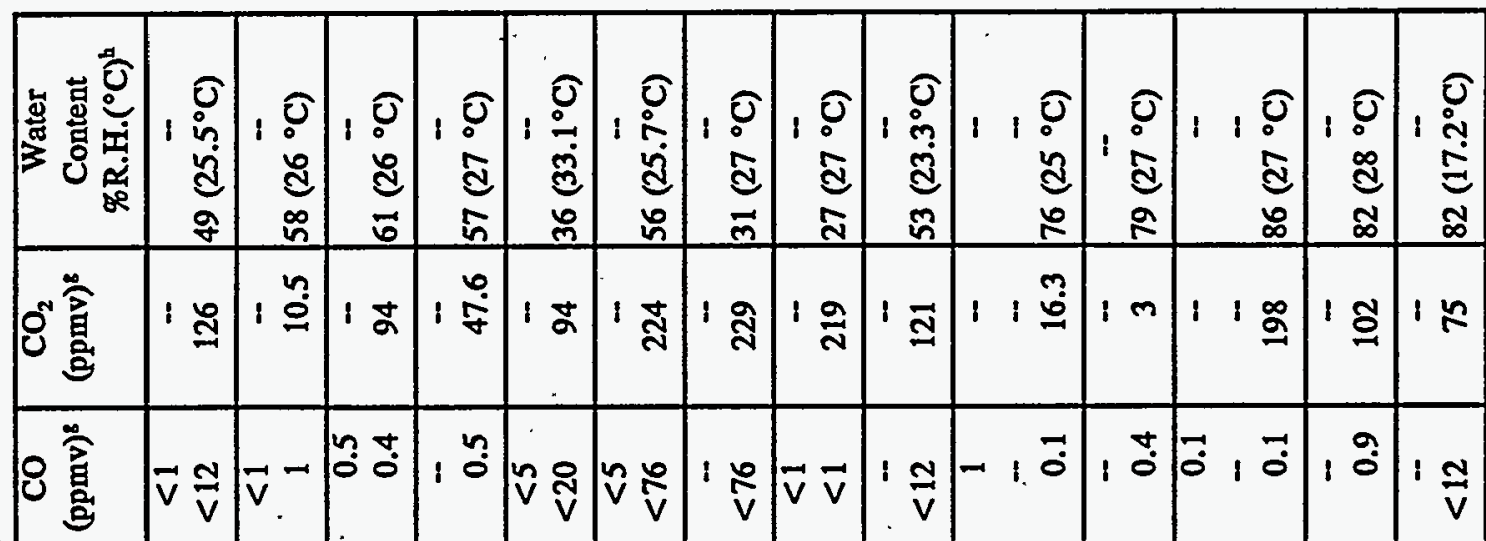

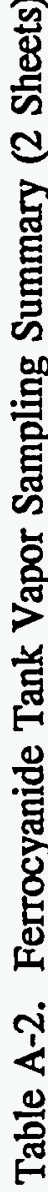

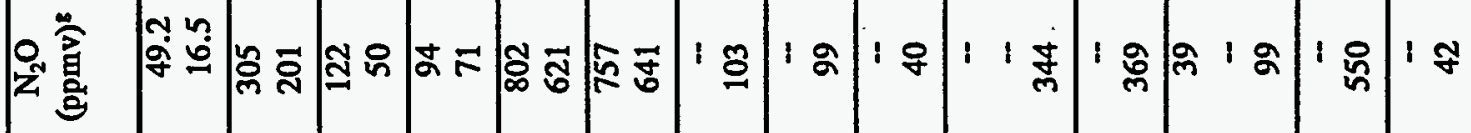

$\sqrt{2}$

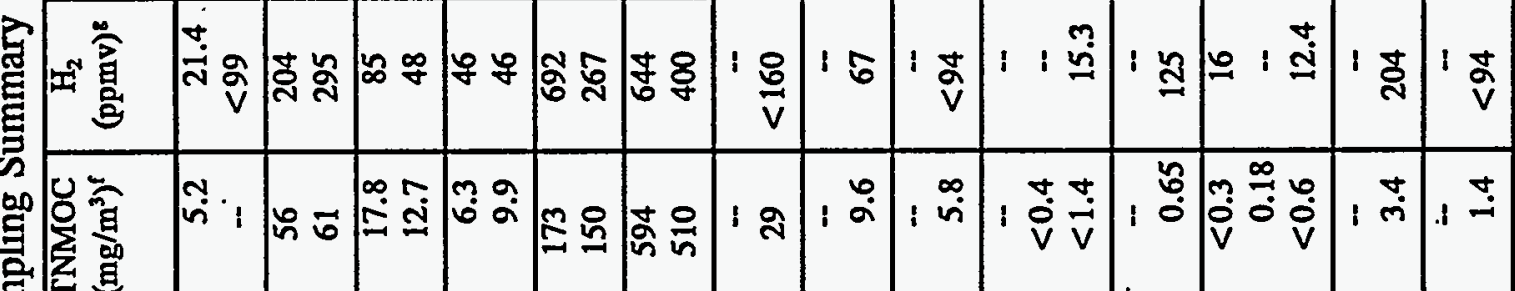

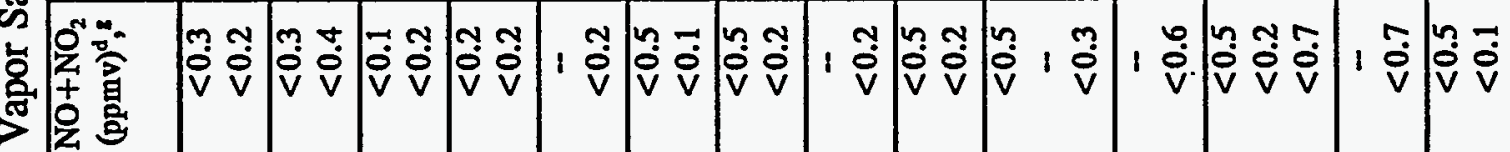

鹿

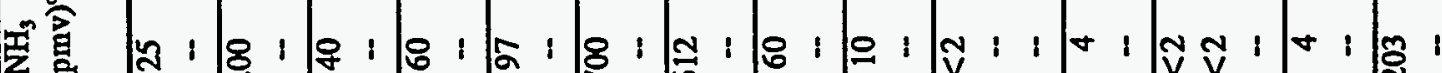

4

,

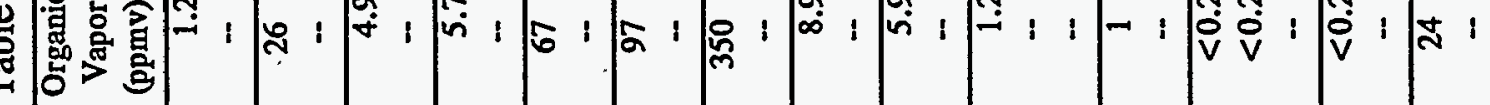

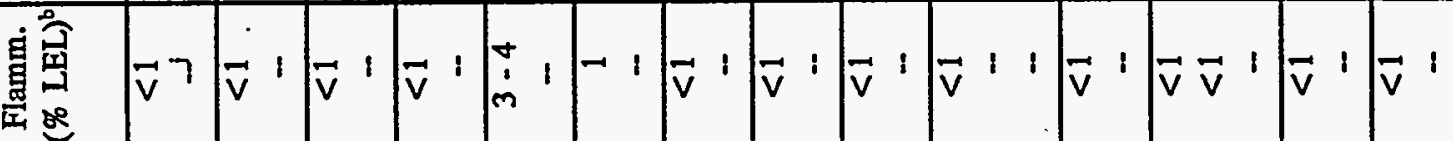

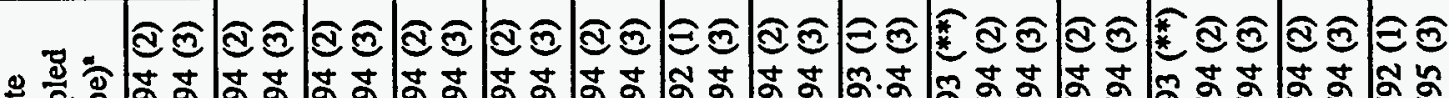

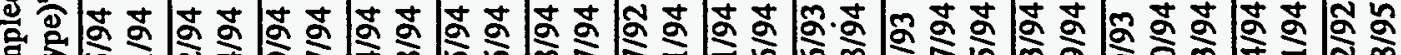

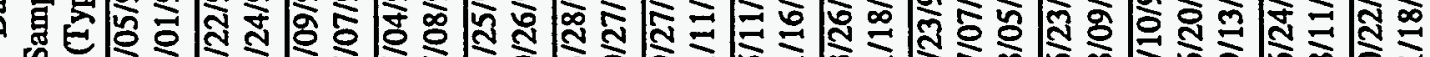

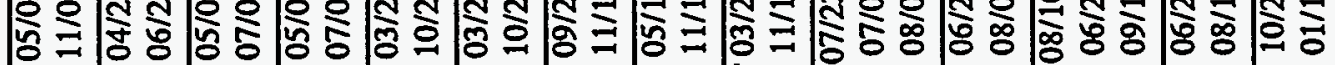

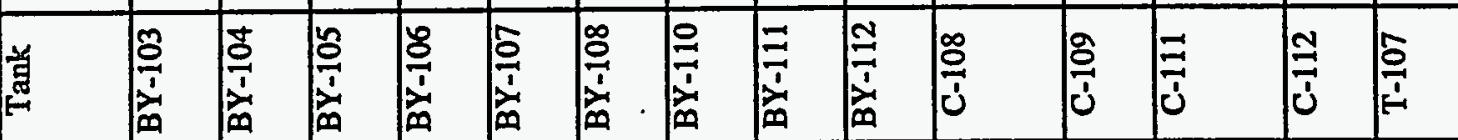


Table A-2. Ferrocyanide Tank Vapor Sampling Summary (2 Sheets)

\begin{tabular}{|c|c|c|c|c|c|c|c|c|c|c|c|c|c|}
\hline Tank & $\begin{array}{c}\text { Date } \\
\text { Sampled } \\
\text { (Type)" }\end{array}$ & $\begin{array}{l}\text { Flamm. } \\
\text { (\% LEL) }\end{array}$ & $\begin{array}{c}\text { Organic } \\
\text { Vapor } \\
\text { (ppmv) }\end{array}$ & $\begin{array}{c}\mathrm{NH}_{3} \\
\text { (ppmv) }\end{array}$ & $\begin{array}{c}\mathrm{NH}_{3} \\
(\text { ppmv) }\end{array}$ & $\begin{array}{c}\text { HCN } \\
\text { (ppmv) }\end{array}$ & $\begin{array}{l}\mathrm{NO}+\mathrm{NO}_{2} \\
(\text { ppmv) })^{\mathrm{d}},\end{array}$ & $\begin{array}{l}\text { TNMOC } \\
\left(\mathrm{mg} / \mathrm{m}^{3}\right)^{f}\end{array}$ & $\begin{array}{c}\mathrm{H}_{2} \\
(\text { ppmv) }\end{array}$ & $\begin{array}{c}\mathrm{N}_{2} \mathrm{O} \\
(\mathrm{ppmv})^{\mathrm{g}}\end{array}$ & $\begin{array}{c}\mathrm{CO} \\
\text { (ppmv) }\end{array}$ & $\begin{array}{c}\mathrm{CO}_{2} \\
(\mathrm{ppmv})^{\mathrm{s}}\end{array}$ & $\begin{array}{c}\text { Water } \\
\text { Content } \\
\text { \% R.H. }\left({ }^{\circ} \mathrm{C}\right)^{b}\end{array}$ \\
\hline TX-118 & $\begin{array}{c}07 / 28 / 93(* *) \\
09 / 07 / 94 \text { (2) } \\
12 / 16 / 94 \text { (3) }\end{array}$ & $\begin{array}{l}<1 \\
<1 \\
-\end{array}$ & $\begin{array}{l}0.3 \\
7.8 \\
--\end{array}$ & $\begin{array}{l}10 \\
28 \\
--\end{array}$ & $\overline{33}$ & $\begin{array}{c}<2 \\
-- \\
-\end{array}$ & $\begin{array}{c}<0.5 \\
<0.5 \\
--\end{array}$ & $\begin{array}{l}- \\
9.3 \\
--\end{array}$ & $\begin{array}{r}- \\
97 \\
<94\end{array}$ & $\begin{array}{l}\overline{17} \\
29\end{array}$ & $\begin{array}{r}\overline{2.5} \\
<12\end{array}$ & $\begin{array}{l}-\overline{54} \\
98\end{array}$ & $\begin{array}{c}\overline{-} \\
\overline{-} \\
42\left(21.5^{\circ} \mathrm{C}\right)\end{array}$ \\
\hline TY-101 & $08 / 04 / 94$ (2) & $<1$ & 4 & 12 & 16 & - & $<0.2$ & - & - & - & - & & \\
\hline TY-103 & $08 / 04 / 94$ (2) & $<1$ & 5 & 30 & 31 & -- & $<0.1$ & - & - & - & - & & \\
\hline TY-104 & $08 / 05 / 94$ (2) & $<1$ & 2.5 & 24 & 50 & - & $<0.2$ & - & - & $=$ & $=$ & & \\
\hline
\end{tabular}

Sample Type:

** Vapor samples taken from in-tank, non-heated tubes utilizing a vapor sampling cart (SUMMA ${ }^{\mathrm{TM}}$ only - no $\mathrm{NH}_{3}$ ).

1 Monitoring performed by Industrial Hygiene technicians using three varying length, non-heated sampling tubes into the tank headspace to evaluate for flammability and toxic vapors; this method is no longer used.

2 In Situ Sampling (ISS) - Sampling is performed by lowering special sorbent traps into the tank headspace that are connected topside to a portable handcart.

3 Sampling involves the mobile vapor sampling system (VSS), heated transfer lines, and installation of a water-heated sampling probe into the tank headspace. All ferrocyanide are scheduled for resampling using this method.

b Measured using a combustible gas meter; LEL = Lower Explosive Limit.

- Measured using a Organic Vapor Monitor (OVM). OVM readings are affected by ammonia; OVM ammonia

response is about 13:1, so that $13 \mathrm{ppmv}$ of ammonia is indicated as $1 \mathrm{ppmv}$ of organic vapors (ppmv = parts per million by volume).

d For Type 1 sampling only; value is measured using colorimetric (Dräger ${ }^{\mathrm{TM}}$ ) tubes (values are estimated, and not quantitative).

c Analyses of ammonia sorbent trap samples.

I Total non-methane organic compound (TNMOC) concentrations measured for SUMMA ${ }^{\mathrm{TM}}$ canister samples.

B Analyses of SUMMA ${ }^{\mathrm{TM}}$ canister samples from Type ${ }^{* *}$, and 3 sampling methods

- \% R. H. is the percent relative humidity calculated from measured dome space water content (mg/L), temperature and atmospheric pressure. Temperature of dome space gas in ${ }^{\circ} \mathrm{C}$ is listed in parentheses.

HCN determinations obtained in selected tanks using a special sorbent trap; values shown are below detection limit of the measurement technique.

f -. Data not yet available or not obtained by this type of sampling. 


\section{DISTRIBUTION}

\section{Number of copies}

\section{OFFSITE}

7

U.S. Department of Energy

EM-36, Trevion II

12800 Middlebrook Road

Germantown, MD 20874

James V. Antizzo, EM-36

Charles O'Dell, EM-36 (5)

Shirley Campbell Grizzel, EH-15

1

U.S. Department of Energy

656 Quince Diamond Road

Room 235, EM-20.1

Gaithersburg, MD 20879

Cynthia Hilland

1

U.S. Department of Energy

Savannah River Operations Office

P.O. Box A

Aiken, SC 29808

Thomas C. Temple

1

Charles S. Abrams

1987 Virginia

Idaho Falls, ID 83404

1

David O. Campbell

102 Windham Road

Oak Ridge, TN 37830

1

Fred N. Carlson

6965 North 5th West

Idaho Falls, ID 83401

1 Billy C. Hudson

202 Northridge Court

Lindsborg, KA 67456 


\section{DISTRIBUTION (Continued)}

Number of copies

OFFSITE

1

William R. Prindle

1556 Crestline Drive

Santa Barbara, CA 93105

1

Alfred Schneider

5005 Hidden Branches Drive

Dunwoody, GA 30338

1

Air Products \& Chemicals, Inc.

7201 Hamilton Blvd

Allentown, PA 18195-1501

George E. Schmauch

1

Battelle Columbus Laboratories

505 King Avenue

Columbus, $\mathrm{OH}$ 43201-2693

James A. Gieseke

1 Brookhaven National Laboratory

Upton, NY 11973

Kamal K. Bandyopadhyay

1 Design Science, Inc.

163 Witherow Road

Sewickley, PA 15143

Gary Powers 


\section{DISTRIBUTION (Continued)}

Number of copies

QFFSITE

1

Fauske and Associates, Inc: 16 W070 W. 83rd St.

Burr Ridge, II 60521

Hans K. Fauske

1

Florida State University

Department of Chemistry B-164

Tallahassee, FL 32306

Greg.R. Choppin

2

G \& $\mathrm{P}$ Consulting, Inc. 3640 Ballard Road

Dallas, OR 97338

J. Michael Grigsby

Arlin K. Postma

1

Harvard University 295 Upland Avenue

Newton Highlands, MA 02161

Melvin W. First

1

Hazards Research Corporation

200 Valley Road, Suite 301

Mt. Arlington, NJ 07856

Chester Grelecki

3

Los Alamos National Laboratory

P.O. Box 1663

Los Alamos, NM 87545

Steve F. Agnew

Steve W. Eisenhawer

Thomas E. Larson 


\section{DISTRIBUTION (Continued)}

Number of copies

\section{OFFSITE}

1

MTT/Department of Nuclear Engineering

77 Massachusetts Ave.

Room 24-102

Cambridge, MA 02139

Mujid S. Kazimi

1 Nuclear Consulting Services, Inc.

P.O. Box 29151

Columbus, OH 43229-0151

J. Louis Kovach

Oak Ridge National Laboratory

1

Emory D. Collins

P.O. Box 2008

7930, MS-6385

Oak Ridge, TN 37831-6385

1 Charles W. Forsberg

P.O. Box 2008

MS-6495

Oak Ridge, TN 37831-6495

1

Thomas S. Kress

P.O. Box 2009

9108, MS-8088

Oak Ridge, TN 37831-8088

$1 \quad$ Rice University

5211 Paisley

Houston, TX 77096

Andrew S. Veletsos 


\section{DISTRIBUTION (Continued)}

2

Sandia National Laboratories

P.O. Box 5800

Albuquerque, NM 87185

Dana A. Powers, MS-0744

Scott E. Slezak, MS-0741

3

Science Applications International Corporation

20300 Century Blvd, Suite 200-B

Germantown, MD 20874

Ray S. Daniels (3)

State of Washington - Department of Ecology

1 Michael T. Gordon

P. O. Box 47600

Olympia, WA $98504-7600$

1

Alex Stone

1315 W. 4th Avenue

Kennewick, WA 99336

1

University of South Carolina

Department of Electrical and Computer Engineering

Swearingen Engineering Center

Columbia, SC 29208

Joseph S. Byrd

1

University of Washington:

Center for Process Analytical Chemistry

Chemistry Department BG-10

Seattle, WA 98195

Bruce R. Kowalski

Vanderbilt University

P.O. Box 1596, Station B

Nashville, TN 37235

Frank L. Parker 


\section{DISTRIBUTION (Continued)}

Number of copies

OFFSITE

1

Waste Policy Institute

555 Quince Orchard Road, Suite 600

Gaitherburg, MD 20878-1437

Donald T. Oakley

ONSITE

10

U.S. Department of Energy,

Richland Operations Office

R. F. Christensen (2)

S7-54

D. H. Irby (4)

S7-54

A. G. Krasopoulos

A4-81

Public Reading Room

$\mathrm{H} 2-53$

RL Docket File (2)

H5-36

7

Pacific Northwest Laboratory

S. A. Bryan

P7-25

R. T. Hallen

P8-38

M. A. Lilga

P8-38

R. D. Scheele

P7-25

C. S. Simmons

K6-77

D. M. Strachan

K9-78

Hanford Technical Library

P8-55

Westinghouse Hanford Company

H. Babad

S7-30

J. B. Billetdeaux

S7-16

D. C. Board

S1-57

W. S. Callaway

X2-10

R. J. Cash (5)

S7-15

M. D. Crippen

L5-31

R. D. Crowe

H0-38 


\section{DISTRIBUTION (Continued)}

Number of copies

ONSITE

D. R. Dickinson

L5-31

G. T. Dukelow

S7-15

M. E. Huda

R3-08

M. N. Islam

R3-08

D. W. Jeppson

L5-31.

N. W. Kirch

R2-11

C. A. Kuhlman

B3-30

E. J. Lipke

S7-14

L. L. Lockrem

S3-90

J. M. McLaren

H0-34

J. E. Meacham (2)

S7-15

N. J. Milliken

H4-62

S. R. Moreno

B3-06

T. V. Rebagay

T6-30

F. R. Reich

L5-63

E. F. Riedel

S3-90

B. C. Simpson

R2-12

H. Toffer

HO-38

W. T. Watson

H0-38

W. D. Winkelman

L5-55

W. D. Wittekind

H0-38

Central Files

L8-04

EDMC

H6-08

OSTI (2)

L8-07

TFIC

R1-20 